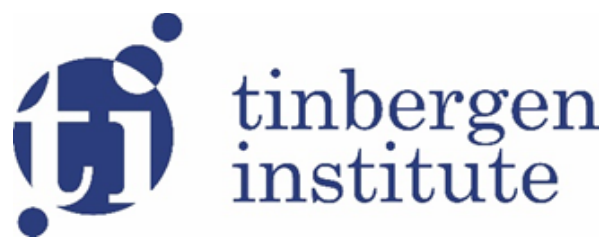

TI 2020-042/VII

Tinbergen Institute Discussion Paper

\section{On the Benefits of Being Alone: Scheduling Changes, Intensity of Competition and Dynamic Airline Pricing}

Yannis Kerkemezos ${ }^{1}$

Bas Karreman ${ }^{2}$

${ }^{1}$ CPB Netherlands Bureau of Economic Policy Analysis

2 Erasmus University Rotterdam 
Tinbergen Institute is the graduate school and research institute in economics of Erasmus University Rotterdam, the University of Amsterdam and Vrije Universiteit Amsterdam.

Contact: discussionpapers@tinbergen.nl

More TI discussion papers can be downloaded at https://www.tinbergen.nl

Tinbergen Institute has two locations:

Tinbergen Institute Amsterdam

Gustav Mahlerplein 117

1082 MS Amsterdam

The Netherlands

Tel.: +31(0)205984580

Tinbergen Institute Rotterdam

Burg. Oudlaan 50

3062 PA Rotterdam

The Netherlands

Tel.: +31(0)10408 8900 


\title{
On the Benefits of Being Alone: Scheduling Changes, Intensity of Competition and Dynamic Airline Pricing
}

\author{
Yannis Kerkemezos ${ }^{* 1,2}$ Bas Karreman ${ }^{1,2,3}$
}

\section{Erasmus School of Economics (ESE) ${ }^{1}$, Tinbergen Institute ${ }^{2}$ and Erasmus Research Institute of Management (ERIM) ${ }^{3}$}

\begin{abstract}
We empirically test the hypothesis that the discounts offered by firms to consumers who purchase tickets in advance increase with the intensity of competition. We develop a new measure of competition for which we use the proximity (in departure time) of a given flight to its competitors to infer the intensity of competition and estimate the impact of competition on advance purchase discounts (APDs) and the dynamic pricing of airlines by exploiting plausibly exogenous changes in the flight schedules of airlines that occur during the booking period. We find strong support for the theoretical prediction that APDs are larger when the intensity of competition is higher using a sample of airline fare quotes. Our results also suggest that airline price dispersion increases with the intensity of competition.
\end{abstract}

Keywords: Dynamic pricing, advance purchase discounts, price discrimination, oligopoly, airlines

JEL Codes: D22, L1, L9, D43

*Corresponding author: Department of Applied Economics, Erasmus School of Economics, Erasmus University Rotterdam, Burgemeester Oudlaan 50, 3062 PA, Rotterdam, The Netherlands. Phone: +31 (0)10 4088928. E-mail: kerkemezos@ese.eur.nl. 


\section{Introduction}

Dynamic pricing strategies are commonly used by firms that sell a perishable good and face aggregate demand uncertainty. Dynamic pricing enables these firms to change prices based on available inventory and time to perishability, a common practice in the pricing of airline tickets, hotel rooms, car rentals and tickets for music or sports events. A frequently used form of dynamic pricing in this context is to offer advance purchase discounts (APDs), where firms charge lower prices at the beginning of the fixed period of time in which the good is available for purchase. APDs can be an optimal pricing strategy for firms selling a perishable good, mainly for two reasons. First, they can assist in covering the large fixed costs of holding (potentially unused) inventories and in improving capacity utilisation (Dana, 1999) ${ }^{1}$. Second, they can facilitate intertemporal price discrimination when consumers are heterogeneous with respect to their preferences to purchase and uncertain about their own demand. This is because APDs induce consumers with weak preferences or low demand uncertainty to purchase in advance and consumers with strong preferences or high demand uncertainty to postpone purchasing (Dana, 1998).

An important concern in this context is understanding how the presence and intensity of competition may affect APDs. Previous theoretical literature shows that offering APDs can be an optimal pricing strategy both in the presence and absence of market power (Gale and Holmes, 1992; Dana, 1998; Möller and Watanabe, 2010), but finds that competition between firms affects the size of the discounts (Gale, 1993; Dana, 1999; Möller and Watanabe, 2016). These studies predict that firms will offer

\footnotetext{
${ }^{1}$ Improving capacity utilisation in this context is also the subject of the extensive operations research literature on revenue management initiated by Gallego and van Ryzin (1994) and Bitran and Mondschein (1997) that considers the problem of dynamically pricing perishable goods over a finite time horizon under different assumptions on market structure, demand uncertainty, product homogeneity and strategic consumer behaviour (e.g., Zhao and Zheng, 2000; Su, 2007; Levin et al, 2009; Martínez-de-Albéniz and Talluri, 2011; Gallego and Hu, 2014).
} 
higher APDs under oligopolistic competition compared to a profit-maximising monopolist. This result is driven by firms' incentive to capture consumers with more certain demands who are willing to purchase early and to prevent losing them to their rivals in the future. Dana (1999) also shows that prices in this setting become more dispersed as a market becomes more competitive, which may suggest that the size of APDs may be positively related to the intensity of competition ${ }^{2}$. Despite the extensive theoretical predictions on the effect of competition on APDs, empirical evidence is still missing. This paper attempts to fill this gap in the literature by studying how competition affects the dynamic pricing (in general) and APDs (in particular) of carriers in the U.S. airline industry.

The airline industry arguably provides a good empirical setting since it closely approximates the context in the models of Gale (1993), Dana (1998, 1999) and Möller and Watanabe (2016). First, airlines choose the number of tickets they would like to offer in advance and any unsold inventory perishes at the time of departure. Capacity, which is also chosen in advance, is relatively costly to modify throughout the booking period. Second, there is individual demand uncertainty and customers are heterogeneous and learn their preferences over time, which provides scope for (intertemporal) price discrimination. Customers with weak time preferences and/or a more certain demand for travel (leisure travellers) are more willing to purchase in advance, while customers with strong time preferences and/or an uncertain demand (business travellers) are willing to postpone purchasing until they can make a more informed decision.

Studying the effect of competition on dynamic airline pricing is an important topic

\footnotetext{
${ }^{2}$ Dana (1999) views a rise in competition, similar to Arrow (1962), as a rise in the number of firms in the industry and a decrease in market concentration. We use the term intensity of competition in a similar way to Boone $(2000 ; 2001)$ and Bonanno and Haworth (1998) to also refer to a rise in competition given the market structure or number of firms. For example, Aghion, Harris, and Vickers (1997) view a switch from Cournot to Bertrand competition as a rise in the intensity of competition. This is because Cournot competition generally leads to higher prices and lower output compared to Bertrand competition, so we can think of the latter as a context where competition is more intense (see also Delbono and Denicolo, 1990; Bester and Petrakis, 1993).
} 
since the vast majority of airline markets are oligopolistic, while previous empirical work in the dynamic airline pricing literature focuses on markets in which firms have monopoly power (Lazarev, 2013; Williams, 2018). Other recent empirical work on airline pricing studies the effect of changes in stochastic demand and available seats on the temporal profile of fares, i.e. the development of prices over time during the booking period (Escobari and Gan, 2007; Escobari, 2012; Alderighi et al, 2015). This work provides evidence for two common regularities in airline pricing, namely that fares monotonically increase with flight occupancy and as the departure date nears. While an increasing temporal profile of fares is evidence for the use of APDs, the effect of competition has not yet been studied directly in this context. Some of the above empirical work only looks at differences between routes with different market structures at a descriptive level or studies potential moderating effects of competition. For example, Alderighi et al (2015) study whether market concentration is a moderator of the effect of available seats on the temporal profile of airline fares.

For our analysis, we collect a unique panel dataset of airline fare quotes for more than 2,300 flights in the 100 busiest U.S. domestic routes based on the number of yearly transported passengers reported by the Bureau of Transportation Statistics (BTS). This comprises a significant share of the U.S. domestic market (approximately $40 \%$ of the total passengers transported). The dataset allows us to track the listed prices of all carriers operating flights in those routes for 95 days prior to the departure and additional information at the flight and ticket level, such as the departure time, fare class and aircraft type. Our dataset differs from previous empirical research on airline price discrimination that uses average quarterly data from the BTS (e.g., Borenstein and Rose, 1994; Gerardi and Shapiro, 2009), but also from previously collected dynamic price data that focuses on a single carrier or offers variation in flights between but not within routes (e.g., Escobari, 2012; Alderighi et al, 2015). 
Since markets in our dataset (and the airline industry) are to a large extent oligopolistic, it is arguably better to measure competition by looking at its intensity while taking market structure as given ${ }^{3}$. The detailed structure of our data allows us to develop a new measure of competition for which we use the proximity (in departure time) of a given flight to its competitors to estimate the intensity of competition between firms. This measure is inspired by the Hotelling model of spatial competition (Hotelling, 1929), where the distance in space becomes equivalent to the distance in time between flights. Measuring competition in this way has several advantages. First, conceptually, it better captures interfirm rivalry and customer stealing motives that may lead to an increase in APDs, which is the underlying mechanism in the models of Gale (1993) and Möller and Watanabe (2016). Second, practically, directly measuring competition by looking at the proximity to rivals eliminates the need to make indirect inferences about the intensity of competition based on the market structure (e.g., market concentration or number of firms).

Our empirical analysis exploits plausibly exogenous changes in flight schedules (i.e. departure time changes or flight cancellations) during the booking period to estimate the impact of competition on APDs and the temporal profile of airline fares. These changes are arguably unrelated to carriers' dynamic pricing decisions but lead to shifts in the relative proximity of competing flights in a day. This has an impact on the $a v$ erage temporal distance of flights (i.e. the average distance in time of a given flight to all competing flights in a day), which is our measure of competition. Furthermore, we analyse the temporal profile of airline fares at the flight level, which allows us to control for route-specific (e.g., route size and airport or route dominance), carrier-specific

\footnotetext{
${ }^{3}$ In the airline industry, the difference between legacy and low-cost carrier competition is a wellknown example of a different intensity of competition for a given market structure. In a recent empirical study of airline fares, Brueckner et al (2013) find, for example, that most forms of legacy carrier competition have a weak effect on average fares, while low-cost carrier competition impacts fares dramatically.
} 
(e.g., cost efficiency and customer loyalty) and flight-specific (e.g., departure time preferences) time-invariant characteristics by means of panel fixed effect techniques. This way we can capture a significant part of the unobserved heterogeneity in prices.

Our work contributes to multiple strands of literature. First, it builds on the extensive theoretical literature on APDs in the dynamic pricing of perishable goods under demand uncertainty (Gale and Holmes, 1992; Gale, 1993; Dana, 1998; 1999; Möller and Watanabe, 2010; 2016) to provide novel empirical evidence of APDs increasing with the intensity of competition. Second, it extends the empirical literature on dynamic airline pricing by studying oligopolistic markets and the effect of competition on the temporal profile of airline prices (Escobari, 2012; Lazarev, 2013; Alderighi et al, 2015; Williams, 2018). Finally, it has implications for the airline price discrimination literature, which studies the effect of competition on price dispersion using average

prices and finds mixed results (Borenstein and Rose, 1994; Gerardi and Shapiro, 2009; Gaggero and Piga, 2011; Dai et al, 2014).

The remainder of this paper is structured as follows. Section 2 discusses the relevant theoretical and empirical literature on APDs and the airline industry. Section 3 discusses the data collection process and introduces our measure of competition and the empirical methodology. Section 4 reports the empirical results of the main and robustness analyses. Finally, Section 5 concludes.

\section{Background}

\subsection{Advance purchase discounts}

Prescott (1975) first developed a model of hotel competition to describe a competitive equilibrium when homogeneous goods are perishable, aggregate demand is uncertain and firms set prices before demand is realised. In this model, which was later for- 
malised by Eden (1990), firms sell goods at several prices, so interfirm and intrafirm price dispersion arises in equilibrium. The Prescott model and its extensions are still frequently used to describe price dispersion in markets where prices vary over time, such as the airline, hotel and car rental industry. Dana (1998) extends the Prescott model and considers firms that offer advance purchase discounts (APD) in a competitive market with heterogeneous consumers and individual demand uncertainty. He shows that APDs may be an optimal (intertemporal) price discrimination strategy for firms even in the absence of market power. The reason that price discrimination arises in equilibrium is that consumers with relatively certain demands and lower valuations have an incentive to purchase the good in advance because the presence of consumers with higher valuations and uncertain demands increases the likelihood of the former being rationed in the spot market ${ }^{4}$. In equilibrium, firms exploit this heterogeneity in preferences and screen consumers based on their demand uncertainty to reduce the costs of holding potentially unused inventory.

Existing literature on APDs also extends these findings from a competitive market to a monopoly (Gale and Holmes, 1992; 1993; Dana, 1999; 2001; Möller and Watanabe, 2010; Nocke et al, 2011). Similar to other price discrimination practices, APDs may promote efficiency by increasing output in markets with elastic demand and assist firms in covering large fixed costs. Gale and Holmes (1992) examine the optimisation problems of a social planner and an unregulated monopolist and find that APDs arise in both solutions and can assist in the efficient allocation of fixed capacity. The authors also show in a different paper that APDs are a profit-maximising pricing strategy because they can help airline monopolists divert demand from peak to off-peak periods (Gale and Holmes, 1993). Möller and Watanabe (2010) show that APDs are part of the monopolist's optimal pricing strategy when consumers face a positive risk of

\footnotetext{
${ }^{4}$ The term spot market is used in a similar way to Dana (1998) to differentiate the immediate purchase from the advance purchase market and is not necessarily related to a market clearing situation.
} 
becoming rationed and provide conditions under which APDs are rational to use in equilibrium. Two relevant conditions for the airline industry are that APDs are found to be profitable when monopolists can implement capacity limits during the purchase period and when capacity is relatively costly and must be chosen in advance.

Previous theoretical work also compares the monopoly equilibrium to a situation with oligopolistic competition, which is relevant for our empirical analysis. These studies show that the use of APDs is a profitable pricing strategy for both monopolists and oligopolists and suggest that the size of the discounts is positively related to the intensity of competition. Gale and Holmes (1992) develop a model that compares the use of APDs in an airline route with two flights in the following situations: (i) both flights are operated by a profit-maximising monopolist, (ii) both flights are operated by a welfare-maximising social planner, and (iii) each one of the flights is operated by a non-cooperative duopolist. They consider equilibria with and without capacity constraints and show that duopolists always have an incentive to employ APDs because that allows them to expand output. In the case of no capacity shortage, they find that duopolists will offer APDs to compete for consumers with elastic demand, while the monopoly and social planner equilibria do not involve APDs. Gale (1993) provides further intuition for that result by comparing a non-cooperative duopoly with a monopoly in a similar setting (i.e. multiple flights on a route departing at different times in a day). He shows that competition to conquer less time-sensitive travellers is stronger in an oligopoly compared to a monopoly. As a result, prices at the lower-end of the fare distribution decrease with competition, which implies that firms implement larger APDs. Möller and Watanabe (2016) also prove this by considering differentiated products in a model of oligopolistic competition with individual demand uncertainty. In their model, firms offer APDs in equilibrium and these discounts are larger in the case of oligopolistic competition compared to a monopoly. The intuition behind this 
result is similar to Gale (1993), namely firms trying to capture customers in advance and prevent losing them to their rival in the future. Finally, Dana (1999) finds evidence for intrafirm price dispersion due to APDs in both the monopoly and oligopoly equilibrium and shows that price dispersion increases as the market becomes more competitive, which is in accordance with patterns documented in the airline industry (Borenstein and Rose, 1994; Stavins, 2001).

\subsection{The airline industry}

The airline industry provides a natural setting to examine the impact of competition on APDs for several reasons. First, the assumptions in the models of Gale and Holmes (1992; 1993), Gale (1993), Dana (1998; 1999) and Möller and Watanabe (2016) are to a large extent satisfied in this context: (i) airline prices are set in advance and tickets have a clear expiration date, changes and cancellations are costly and resale is not possible (perishability), (ii) airlines choose their capacity in advance and adjustment throughout the booking period is relatively costly (high marginal cost of capacity), and (iii) customers can be divided into two distinct categories with respect to their certainty to fly and departure time preferences, i.e. leisure (business) passengers with a relatively certain (uncertain) demand to fly and low (high) time sensitivity (customer heterogeneity and individual demand uncertainty). Second, there is robust empirical evidence of airlines using APDs in their pricing strategies and APDs partly explain (together with the impact of available seats and revenue management) the increasing temporal profile of fares documented in previous literature (Alderighi et al, 2015; Williams, 2018). Third, while airlines compete in oligopolistic settings, the effect of competition on dynamic pricing and APDs has not been previously studied empirically.

Moreover, studying the effect of competition on airline price dispersion is incomplete without taking into account the impact of APDs. An increase in APDs due to 
more competition would partially contribute towards a positive relationship between competition and price dispersion. This occurs since fares at the lower-end of the price distribution, usually offered by carriers at the beginning of the booking period, decrease as competition increases. Existing empirical literature on the effect of competition on airline price dispersion has so far not explicitly considered the intertemporal dimension and APDs, mainly due to the lack of available dynamic pricing data. This is a likely explanation for the mixed results previously reported. For example, Borenstein and Rose (1994) study price dispersion by using average price data and report substantial variation in airline fares, which they interpret as indirect evidence for price discrimination. The authors find that the dispersion in prices is higher on routes with more competition or lower flight density. Stavins (2001) also finds that price dispersion decreases with market concentration by using ticket restrictions (e.g., Saturday-night stayovers or advance purchase requirements) as a proxy for price discrimination. Gerardi and Shapiro (2009) study the effect of carrier entry on price dispersion by using a panel of average price data and provide evidence of the opposite effect, namely that price dispersion decreases with competition. Gaggero and Piga (2011) also report a similar finding. These authors argue that increased competition and a loss in market

power hinder the ability of firms to price discriminate between business and leisure travellers, leading to lower fares at the higher-end of the price distribution.

\section{Data and methodology}

\subsection{Data collection}

Our data was collected using a web scraper that extracted listed price data of airline tickets from two online sources: (i) ITA Matrix, which is an airline ticket price aggregator website and (ii) the official website of Southwest Airlines, since Southwest does 
not publish its fares on other platforms. The web scraper was programmed to collect the cheapest available economy class ticket prices for all departures of all carriers operating flights in the 100 busiest U.S. domestic routes based on the number of yearly transported passengers in 2017, as reported by the Bureau of Transportation Statistics $(\mathrm{BTS})^{5}$. The data was collected between July and October 2018 and all flights depart on Monday, October $22^{\text {nd }}, 2018$. The web scraper collected data every day at the same time starting from 95 days prior to the departure date and up until the day before departure. The carriers in our dataset are Alaska, American, Delta, Frontier, Hawaiian, JetBlue, Mokulele, Southwest, Spirit and United. Our final panel dataset consists of 2,338 direct, non-stop, one-way flight departures operated by those carriers in the 100 routes (origin and destination airport pairs) and 95 observations over time for each flight. In addition to the listed ticket price, we also collected the following information: flight departure time, flight arrival time, flight duration, fare class and operating aircraft ${ }^{6}$.

The structure of the collected data allows us to consistently examine the effect of competition on the temporal profile of fares and control for confounding sources of variation in airline prices. First, by using one-way rather than round-trip tickets, we control for the price variation resulting from ticket restrictions such as Saturday-night stayovers, or minimum/maximum stay requirements. Second, by only using direct, nonstop flights, we control for potential price variation due to more complex itineraries that are not likely to be viewed as perfect substitutes by consumers (e.g., connecting flights). Third, by restricting tickets in our sample to the cheapest available economy class and excluding business and first class tickets, we limit the available classes of fares and reduce price variation due to cost-related reasons. Fourth, by recording

\footnotetext{
${ }^{5}$ A detailed list of all routes used in our sample can be found in the Appendix of this paper.

${ }^{6}$ We also collected data for two more departure dates that we use in robustness analyses. The data was collected using the procedure that is described in Section 3.1. The additional departure dates are Monday, January $28^{\text {th }}, 2019$, and Thursday, January $31^{\text {st }}$, 2019. All dates were selected so that they do not coincide with (or are close to) any public holidays or other significant events.
} 


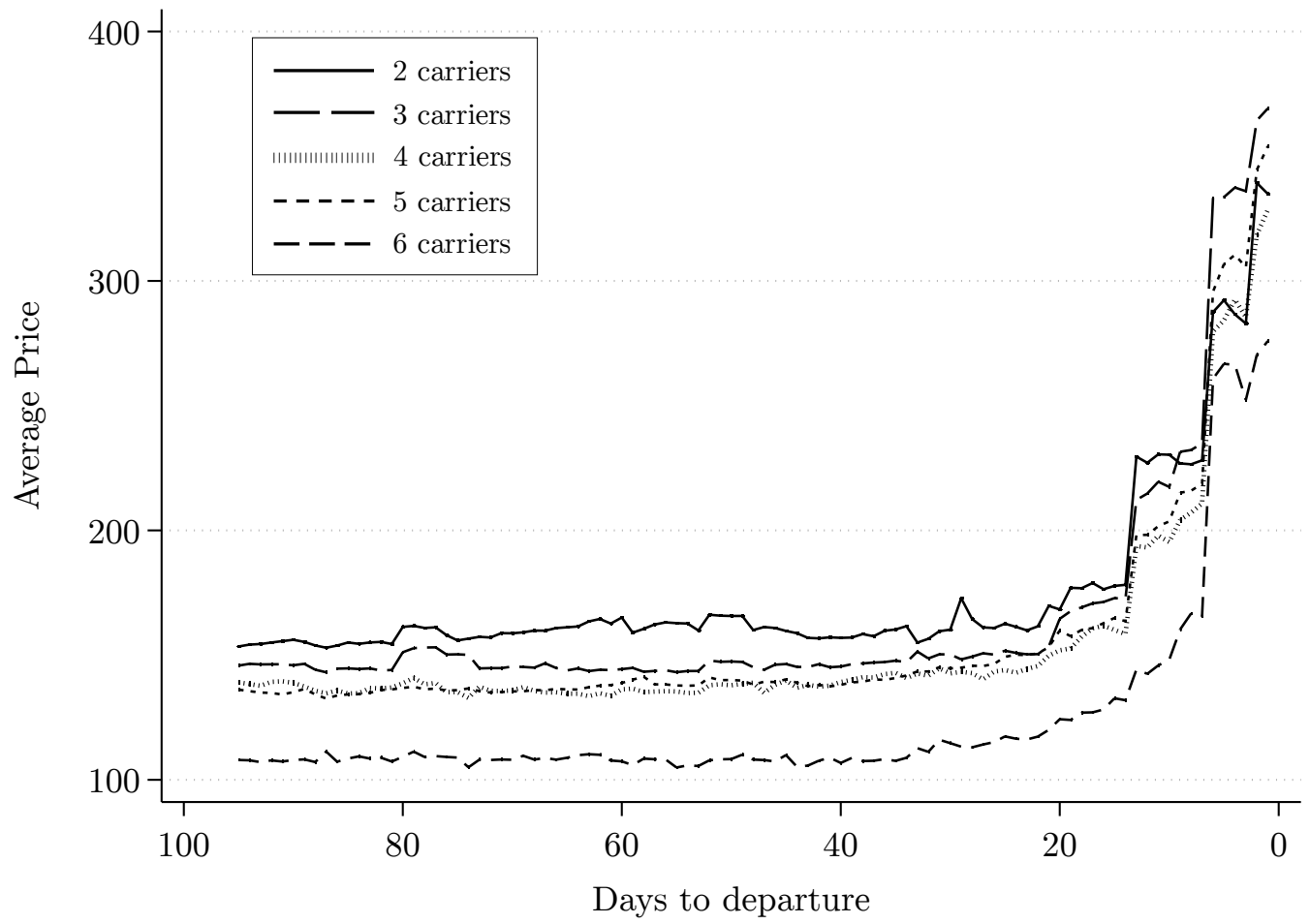

Figure 1 Temporal profile of the average fare in routes with a different number of operating carriers. Refer to the legend in the figure for information on the different groups.

fare class information, we are able to control for potential price variation resulting from tickets with a higher degree of flexibility that may not be comparable to the (usually) inflexible APD tickets. Finally, selecting a fixed departure date limits the variation in demand that may arise by, for example, comparing flights in the same route that depart at different dates. A unique feature of our data is that it combines information on all flights on the selected routes with a fixed departure date, which implies that all carriers and flights in a given route are exposed to the same demand shocks at every given point in the booking period. 


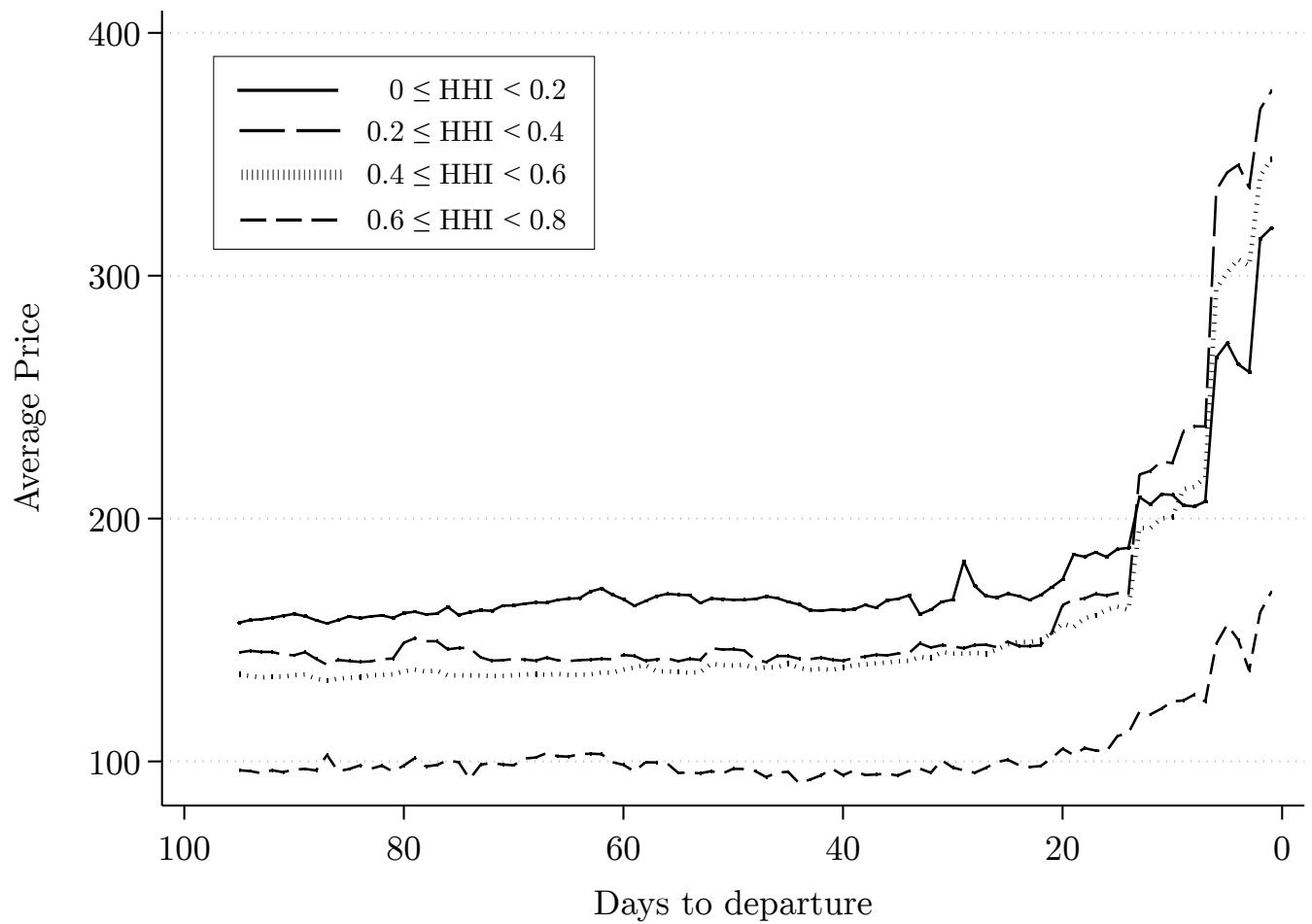

Figure 2 Temporal profile of the average fare in routes with a different Herfindahl-Hirschman Index (HHI). Refer to the legend in the figure for information on the different groups.

\subsection{Descriptive evidence of APDs increasing with competition}

In this section, we provide descriptive evidence of the effect of competition on APDs by looking at the temporal profile of fares in routes with a different market structure. Figure 1 plots the temporal profile of the average fare in 5 groups of routes, each with a different number of operating carriers. Figure 2 plots the average fare in 4 groups of routes with a different Herfindahl-Hirschman Index (HHI). We observe that average fares exhibit an increasing temporal profile, with a relatively steady development until about 20 days before departure and a steep increase in the remaining days before departure. Similar to previous empirical work in dynamic airline pricing, there is clear evidence of carriers using APDs irrespective of the market structure. Moreover, an increase in competition appears to have a significant impact on the size of those 
discounts. Prices in routes with more carriers and routes with lower concentration, as measured by the HHI, are lower early in the booking period (until about 20 days before departure). After that point fares begin to converge and there is no clear ordering based on the market structure neither for the number of carriers nor the HHI groups ${ }^{7}$. As a result, intertemporal price dispersion appears to be increasing with competition.

\subsection{Measuring the intensity of competition}

While the above evidence does provide some insight into the effect of competition on APDs, a cross-sectional comparison of routes with a different market structure is problematic in this context for two reasons. First, it is subject to several confounding factors that could bias the analysis and are difficult to measure, such as customer heterogeneity, departure time preferences and route-specific carrier pricing strategies. A solution to this issue would be to perform an analysis at the flight level in order to control for time-invariant route, carrier and flight characteristics by means of panel fixed effects techniques. However, this is not possible with existing measures of competition, such as market structure indicators and concentration indices, because these are fixed at the route level. Second, economic theory of oligopolistic competition and empirical evidence from the airline industry suggest that it may not always be correct to assume there is a one-to-one relationship between the intensity of competition and market structure or concentration $^{8}$. As a result, using indicators of market structure would only allow making indirect inferences about the intensity of competition and may fail to capture the interfirm rivalry and customer stealing motives that drive the effect of

\footnotetext{
${ }^{7}$ An exception in this classification is the lowest HHI group $(0 \leq \mathrm{HHI}<0.2)$. The average price of that group remains significantly lower compared to the other HHI groups, also during the final 20 days before departure.

${ }^{8}$ An example with different intensities of competition for a given market structure from the theory of oligopolistic competition is discussed in Footnote 2. An example from the empirical airline literature is discussed in Footnote 3.
} 
competition on APDs in the models of Gale (1993) and Möller and Watanabe (2016).

To address the above issues, we develop a new measure for the intensity of competition by exploiting information on the departure time of each flight, which is a unique feature of our dataset. The idea of this measure is based on the Hotelling model of spatial competition (Hotelling, 1929), which we extrapolate to the temporal dimension. Borenstein and Netz (1999) use a similar application of the Hotelling model to airline flight departures to study the effect of competition on differentiation. In the original Hotelling model, firms compete in prices and must decide where to locate on a linear stretch with uniformly distributed consumers. In this setting, firms face a trade-off between locating close to their competitors in order to steal customers and locating farther away from their competitors in order to increase differentiation and reduce price competition. Different assumptions explored by the main theory and extensions of the Hotelling model (e.g., Eaton and Lipsey, 1976; d'Aspremont et al, 1979; Osborne and Pitchik, 1985; Anderson, 1987) cause either one of these forces to dominate, leading to a location choice with minimum differentiation and maximum price competition (i.e. close to competitors) or maximum differentiation and minimum price competition (i.e. far away from competitors).

In our context, airline competition can be analysed using the spatial Hotelling framework, where the location of each flight is equivalent to the time of departure in a 24-hour time frame and the distance to competitors is equivalent to the temporal distance between flights in minutes. Consumers are not located physically, but over time by having preferred departure times (Douglas and Miller, 1974). In our application, we are not concerned with the location choice of a particular firm but take that as given and use it to infer the intensity of price competition with other firms. Location choice is not relevant in our analysis, since airlines announce their schedules in advance of the booking period and compete in prices given their predetermined choice. Once 
the booking period has started, location choice is no longer a strategic variable for airlines since intermediary changes are (prohibitively) costly ${ }^{9}$.

To construct our competition measure we calculate pairwise the temporal distance of a given flight to all other flights on a route and then compute the average of those distances, which we define as the average temporal distance (ATD) of a flight. This is different from Borenstein and Netz (1999), which looks at flight density (i.e. whether flights are evenly distributed over the day) by computing the average distance between flights. Our measure is therefore a flight-level measure of the relative temporal proximity to competition. We assume that the intensity of competition monotonically increases as the temporal distance to competing flights decreases. The advantage of our setting is that airline departures within a day are relatively homogeneous after controlling for departure time preferences and carrier specific unobservables (e.g., cost heterogeneity or customer loyalty). This implies that any remaining difference in prices can be attributed to the effect of competition, which we can measure with the ATD.

The average temporal distance (ATD) of a given flight $i$ on a route $k$, is calculated as follows:

$$
\operatorname{ATD}_{i k}=\frac{1}{n-1} \sum_{i=1}^{n-1} \sum_{j>1}^{n} \min \left[\left|d_{i}-d_{j}\right|, 24-\left|d_{i}-d_{j}\right|\right]
$$

where $n$ denotes the number of daily flight departures on the route, $d$ denotes the departure time and $j$ denotes other flights on the route during the day ${ }^{10}$. An example of the calculation of the ATD is given in Figure 3. In this example, there are 5 flights on a route departing at $7 \mathrm{am}, 11 \mathrm{am}, 12 \mathrm{pm}, 4 \mathrm{pm}$ and $8 \mathrm{pm}$. To find the ATD of the early morning flight, we compute the temporal difference (in hours) of that flight with each one of the other departing flights on the route (4, 5, 9 and 13 hours, respectively) and then calculate the average, which is equal to 7.75 hours. This procedure is repeated

\footnotetext{
${ }^{9}$ We further elaborate on the assumption that scheduling changes during the booking period are prohibitively costly for airlines in Section 3.4.

${ }^{10}$ The number 24 appears in Equation 1 because this is the number of hours in a day.
} 

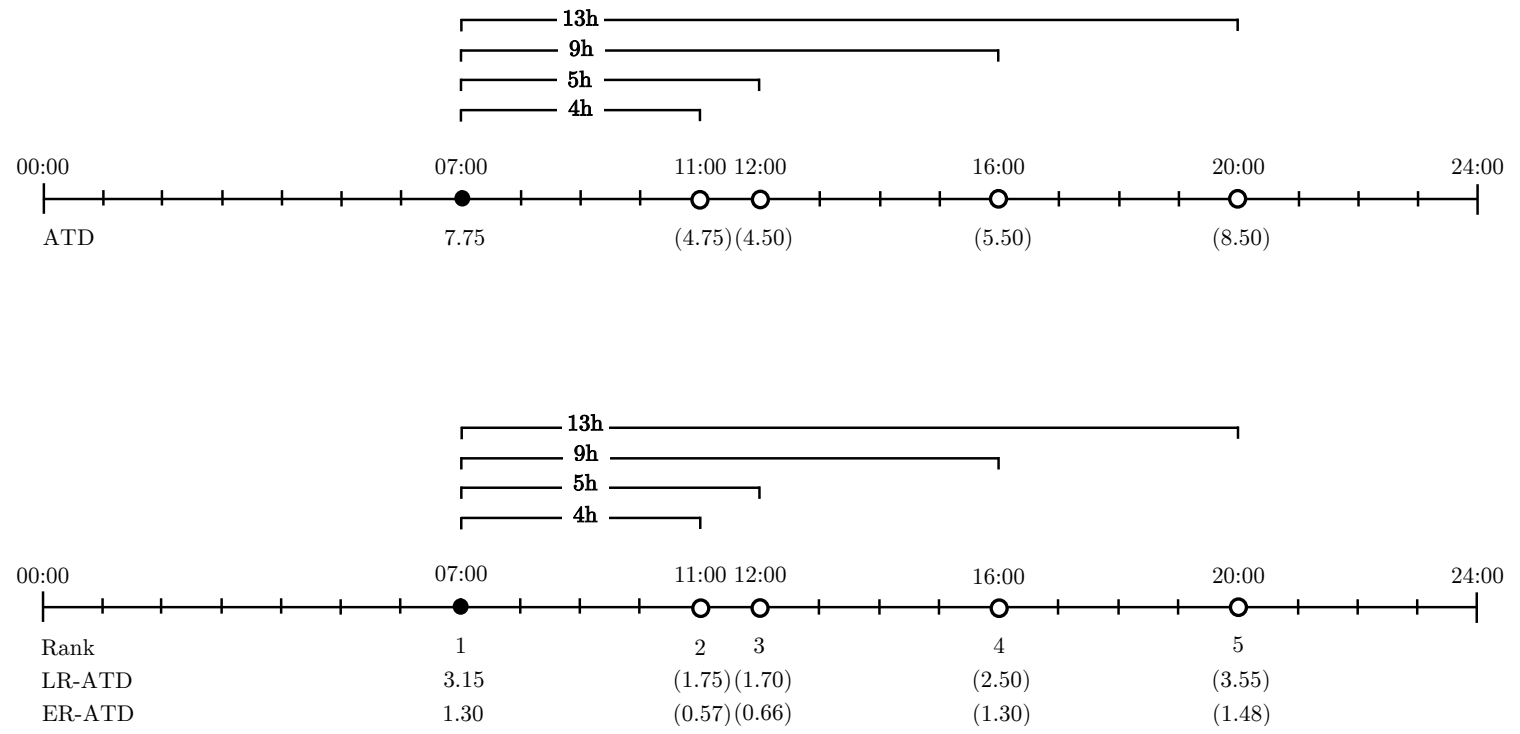

Figure 3 Example of flight departures on a route for the calculation of the ATD, LR-ATD and ER-ATD. The value of the respective measure for each flight is reported below each departure time.

for each one of the departing flights on the route. The ATDs of the remaining flights in the example are reported below the departure time of each flight in Figure 3.

The ATD measure in Equation 1 has a number of limitations. First, all flight pairs are given equal weight in the calculation of the average. While it may be reasonable to assume that all same-day flights on a route compete with each other, it is not likely that they all compete to the same extent. For example, a flight scheduled at 8am likely competes with other morning departures at 10am and 11am but may not compete with evening departures scheduled at $7 \mathrm{pm}$ and $9 \mathrm{pm}$. Second, flights departing early in the morning or late in the evening have significantly higher ATDs since they only face one-sided competition (i.e. competition from flights later/earlier during the day, respectively). The ATDs of flights departing in between those times are significantly lower on average since they face two-sided competition (i.e. competition from both 
earlier and later flights) ${ }^{11}$. This problem is exacerbated by the fact that our data concerns a specific departure date, which means we miss information on flights departing on the previous and following day. This type of censoring is especially important for the early morning and late evening flights. For example, a flight departing at 11:30pm on Monday, October $22^{\text {nd }}$ likely competes with another flight departing at 12:30am on Tuesday, October $23^{\text {rd }}$, which is not in our dataset.

We address these issues by adding weights to the calculation of the ATD. These weights are designed in such a way that the distance to immediate neighbours of a given flight becomes more important in the calculation of the average $^{12}$. First, we rank all competing flight departures based on their distance to a given flight in ascending order. This implies that the closest competing flight departure is ranked first and the farthest competing flight departure is ranked last ${ }^{13}$. In the example of Figure 3 , flights are therefore ranked as follows: $11 \mathrm{am}\left(1^{\text {st }}\right), 12 \mathrm{pm}\left(2^{\text {nd }}\right), 4 \mathrm{pm}\left(3^{\text {rd }}\right)$ and $8 \mathrm{pm}\left(4^{\text {th }}\right)$. Second, we use one of the following weights for each departure time difference pair $\left|d_{i}-d_{j}\right|$ depending on the rank $r$ :

$$
\begin{array}{rll}
\text { Linear rank : } & \max [0,1-\alpha \cdot r] & \alpha_{\in}[0,1] \\
\text { Exponential rank : } & \beta^{r} & \beta_{\in}[0,1]
\end{array}
$$

We define the following two ATD measures, which we use in our main and robustness analyses: (i) the Linear Rank Average Temporal Distance measure (LR-ATD),

\footnotetext{
${ }^{11}$ This should not be surprising since the ATD is designed to measure the temporal proximity to competition. Early morning and late evening flights are further away from other competing flights during the day, which will be captured by the measure. However, the problem in this case is that calculating the ATD in Equation 1 leads to highly dispersed ATD values and large outliers (i.e. the early morning and late evening flights) in the distribution of ATDs in a particular route.

${ }^{12}$ Borenstein and Netz (1999) also look at two measures in which immediate neighbours become more important in the calculation of their (route-level) measure of the average distance between flights.

${ }^{13}$ In the case that several competing flights depart at the same time, they are all assigned the same rank (and thus weight) in the calculation of the average.
} 
which uses the linear weight, and (ii) the Exponential Rank Average Temporal Distance measure (ER-ATD), which uses the exponential weight. The parameters $\alpha$ and $\beta$ measure the extent to which same-day flight departures compete with each other. When $\alpha$ is near 0 ( $\beta$ is near 1$)$ then all same-day flight departures are assumed to compete equally and have a similar weight in the calculation of the average. As $\alpha$ is approaching 1 ( $\beta$ is approaching 0 ), direct neighbours in departure time become increasingly more important in the calculation of the average ${ }^{14}$.

We calculate below the LR-ATD and ER-ATD of the early morning flight from the example in Figure 3, assuming that $\alpha=\frac{1}{5}$ and $\beta=\frac{1}{2}$, respectively:

$$
\begin{array}{ll}
\text { LR-ATD }_{07: 00}=\frac{1}{4}\left[\frac{4}{5}|7-11|+\frac{3}{5}|7-12|+\frac{2}{5}|7-16|+\frac{1}{5}|7-20|\right] & =3.1 \\
\text { ER-ATD }_{07: 00}=\frac{1}{4}\left[\frac{1}{2}|7-11|+\frac{1}{4}|7-12|+\frac{1}{8}|7-16|+\frac{1}{16}|7-20|\right] & \simeq 1.3
\end{array}
$$

The LR-ATD and ER-ATD of all other flights in the example are also reported under each departure time in Figure 3. The dispersion in ATDs is significantly reduced as a result of the introduction of the weights.

Our measure is highly flexible and the introduction of weighting offers many possibilities for accurately measuring the intensity of competition. For example, we can exclude flights of the same carrier from the calculation of the ATD of a given flight (interfirm weighting). This is likely important since many routes in our sample have a large number of daily departures but only a few operating carriers. Not accounting for the fact that flights of the same carrier likely do not compete with each other may erroneously give the impression that competition is high when in fact it is not. Similarly, our measure can take strategic alliances into account by excluding flights

\footnotetext{
${ }^{14}$ When $\alpha=0$ or $\beta=1$, all competing flights receive the same weight and the two measures become equivalent to the ATD in Equation 1. In the extreme case when $\alpha=1$ or $\beta=0$, all competing flights receive zero weight irrespective of their distance to a given flight. This can be interpreted as flights only competing with other flights departing at the exact same time during the day.
} 
operated by alliance partners of a given carrier from the calculation of the ATD (alliance weighting). Another option is to take into account the type of competitor in the calculation of the ATD. For example, previous literature in airline competition finds low-cost carrier competition to have a dramatic impact on average fares in contrast to most forms of legacy carrier competition, which is found to have weak effects on fares (e.g., Brueckner et al, 2013). Giving different weights to competing flights depending on the type of competitor (e.g., legacy or low-cost carrier) would be a way to incorporate that in the calculation of the ATD (competitor-type weighting).

\subsection{Empirical strategy}

\subsubsection{Changes in flight schedules}

To perform an analysis at the flight level, we exploit plausibly exogenous changes in flight schedules that occur during the booking period, such as departure time changes and flight cancellations ${ }^{15}$. Scheduling changes that occur throughout the booking period are likely related to carrier or airport specific operational reasons (e.g., aircraft availability, network coordination or slot availability) and are unlikely to be related to carrier pricing strategy decisions. Rescheduling flight departures throughout the booking period is (prohibitively) costly for carriers for many reasons, such as administrative costs for dealing with passengers who have already booked a ticket, customer dissatisfaction, and increased risk of cancellations and compensation claims. Figure 4 presents the frequency of changes in the ATD of a flight throughout the booking period. A large number of changes is concentrated at the beginning and the end of

\footnotetext{
${ }^{15}$ The ATD measures are flight-level measures and will be constant in the time period of 95 days until departure in our sample when the relative position of competing flights does not change. To ensure there is variation in ATD at the flight level, it is thus necessary that flights change position (i.e. departure time) in the time span in which our data is collected. In this case, this happens as a result of changes in the schedules of flights.
} 
the booking period, but there is a sufficient number of changes occurring during the entire time span of our sample ${ }^{16}$. By definition, a change in the schedule of one flight will alter the ATDs of all same-day flights on a route. As a result, the 321 changes in departure time that occur throughout the booking period in our sample lead to many more exogenous shocks to our measure of competition, which helps to identify the effect of competition on the temporal profile of fares and APDs ${ }^{17}$. The changes in departure time in our sample are approximately 15 minutes on average and 95\% of those departure time changes is less or equal to an hour.

\subsubsection{Main empirical specification}

To study how airline prices change with competition during the booking period, we estimate the following reduced-form pricing equation:

$$
\operatorname{Ln}(\mathrm{P})_{i k t}=c+\sum_{t=1}^{T-1} \lambda_{1 t} \mathrm{BD}_{t}+\sum_{t=1}^{T} \lambda_{2 t}\left(\mathrm{LR}-\mathrm{ATD}_{i k t} \times \mathrm{BD}_{t}\right)+\eta_{i k}+\varepsilon_{i k t}
$$

\footnotetext{
${ }^{16}$ Three types of events may cause the ATD of a given flight to change: (i) the departure time of that flight or (at least) one of its competing flights changes, (ii) (at least) one of its competing flights is cancelled, (iii) (at least) one of its competing flights is fully booked (i.e. economy class tickets are no longer available). Since we observe the departure time of a flight, we can distinguish changes in ATD due to departure time changes from flight cancellations and fully booked flights. However, we can not distinguish flight cancellations from fully booked flights because a flight would exit our dataset in both cases. Fully booked flights are likely the reason for the large increase in the frequency of changes in the ATD during the last 5 days before departure. Flight cancellations are likely random events and thus not expected to be concentrated at a specific time during the booking period. We use all three types of events in our main analyses and control for non-departure time related changes in ATD in robustness analyses, which yield the same qualitative results.

${ }^{17}$ Changes due to flight cancellations and fully booked flights are not included in this number.
} 


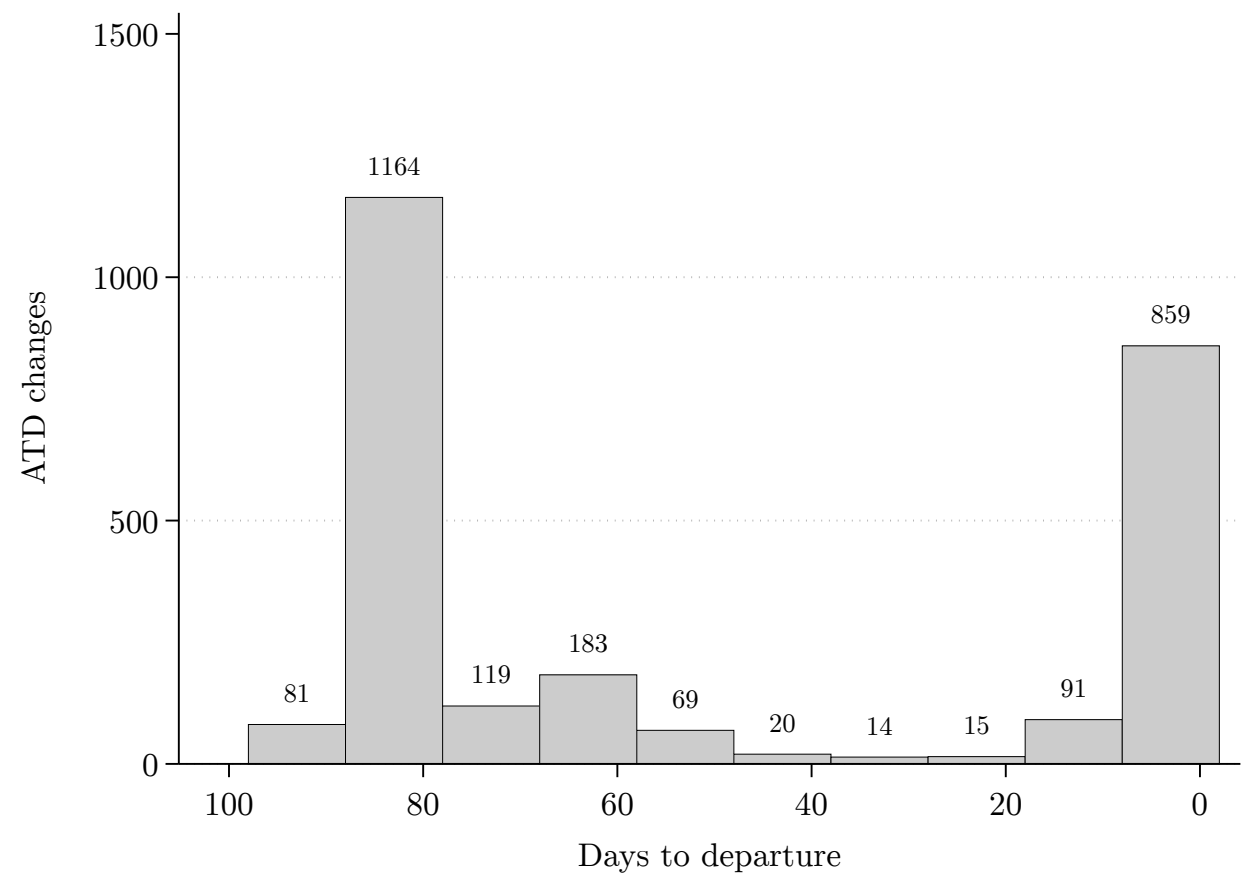

Figure 4 Frequency of changes in the average temporal distance (ATD) of flights throughout the booking period. The changes in ATD are grouped into periods of 10 days.

where $i$ denotes a flight-carrier combination, $k$ denotes a route, $t$ denotes the day of the booking period and $T$ the total number of days during which we track prices ${ }^{18}$. The dependent variable $\operatorname{Ln}(\mathrm{P})_{i k t}$ is the logarithm of the listed price at the routecarrier-flight level and competition is measured by LR-ATD $i k t$ (as in Equation 2) or ER-ATD $i k t$, which also vary at the route-carrier-flight level. We use interfirm weighting and thus assume that same-day departures of the same carrier do not compete with each other ${ }^{19} . \mathrm{BD}_{t}$ is an indicator variable for each day of the booking period (e.g., $\mathrm{BD}_{1}=1$ if $t=1$ and is equal to 0 otherwise). These indicator variables are used to model a baseline temporal profile of fares ${ }^{20}$. We interact LR-ATD $i k t$ (or ER-ATD $\left.i k t\right)$

\footnotetext{
${ }^{18}$ We start tracking prices 95 days prior to the departure, which implies that $t_{\in}\{1,2, \ldots, 95\}$ and $T=95$.

${ }^{19}$ We further assume that $\alpha=\frac{1}{5}$ and $\beta=\frac{1}{2}$ for the calculation of the LR-ATD and ER-ATD, respectively. We change the values of $\alpha$ and $\beta$ in robustness analyses and find the same qualitative results.

${ }^{20}$ This approach is similar to previous empirical work in airline dynamic pricing, such as Escobari (2012) and Alderighi et al (2015).
} 
with the booking day dummies to allow the estimated effect of competition on the temporal profile of fares to be different throughout the booking period. Finally, term $\eta_{i k}$ denotes the (route-carrier-flight) fixed effects, $c$ is a constant term and $\varepsilon_{i k t}$ is an error term. The included fixed effects allow us to control for time-invariant route, carrier and flight characteristics that may affect ticket prices. Route specific effects include the size and distance of a route, local population and income, and airport or hub dominance at origin and destination. Carrier specific effects include brand loyalty, carrier type (e.g., legacy or low-cost) and cost structure. Flight specific effects include operating aircraft and load factor efficiency, and customer preferences with respect to a given departure time. Departure time preferences are important to take into account as they may impact the demand for a particular flight. While a flight that is positioned far away from competitors may experience less direct price competition, the lack of neighbouring flight departures may also indicate an unpopular departure time. This confounding effect is controlled for in our analysis since our coefficients are estimated by using the variation at the flight level, i.e. holding departure time preferences constant.

Another challenge in the dynamic pricing context is taking into account the effect of available seats on fares. Prices in the airline industry are simultaneously determined by fares responding to both time to departure and available seats at the moment of purchase (Alderighi et al, 2015; Williams, 2018). To control for the effect of available seats on fares, real-time capacity data at the flight level would be necessary. However, available capacity data is carrier sensitive information and is to our knowledge not possible to obtain, especially for a large sample of routes, carriers and flight departures that would be required for the analysis of competition. Previous research has relied on online seat maps to estimate available seats at any given point in time (e.g., Escobari 2012, Alderighi et al, 2015; Williams, 2018). This approach has two drawbacks. First, collecting seat map data for many routes and flights is cumbersome and costly as the 
information is only available through paid airline global distribution systems, such as Amadeus or SABRE. Second, and more importantly, seat map data is not likely to be a good indicator of real-time available flight capacity ${ }^{21}$. The reason is that carriers nowadays commonly charge an additional fee for an advance seat selection. As a result, many travellers select their seats during check-in, i.e. only a couple of days to hours before the flight departure. This type of measurement error likely leads to a systematic overestimation of the number of available seats throughout the booking period.

In our analysis, controlling for the effect of available capacity on fares is less important. Since the identification of the effect of competition on dynamic pricing and APDs is based on plausibly exogenous changes in flight schedules, it is arguably sufficient to ensure that these changes are not also related to changes in the availability of seats. An example of this would be carriers changing the departure time of a flight in order to use a bigger or smaller aircraft, which would also affect the number of available seats. To ensure that changes in schedules are not related to changes in aircraft and the available capacity, we extend Equation 2 with two types of control variables: (i) aircraft-type fixed effects, and (ii) a (route-carrier-flight level) indicator variable for changes in operating aircraft that occur during the booking period. Finally, to further capture the effect of available capacity on fares, we include fare class fixed effects in Equation 2 to control for the lowest available fare class at a given day during the booking period ${ }^{22}$. The available fare class is related to the number of available seats due to fencing, i.e. booking limits that airlines implement as a result of revenue management

\footnotetext{
${ }^{21}$ The issue that online seat maps may not accurately represent real-time flight loads and lead to a measurement error is also acknowledged by Williams (2018).

${ }^{22}$ We create three fare class groups for economy tickets in our dataset: Economy Low, Economy Medium and Economy High. Each carrier's fare classes (in most cases more than 10) are then allocated to those groups based on information about ticket flexibility (e.g., whether tickets can be changed), ticket restrictions (e.g., whether ticket cancellations are refundable) and ticket privileges (e.g., whether tickets offer additional frequent flyer points) from each carrier's website. This information is not publicly available for three carriers in our sample: Frontier, Mokulele and Spirit.
} 
practices, but can also help control for ticket heterogeneity since it likely captures some of the variation in prices due to ticket restrictions and flexibility.

\section{Empirical analysis}

\subsection{Main results}

Table 1 presents the results of our main analysis on the effect of competition on the dynamic pricing of airlines ${ }^{23}$. To facilitate the interpretation of the estimated coefficients, we normalise the LR-ATD (ER-ATD) with interfirm weighting that is used in our analyses. Since the dependent variable is the logarithm of the listed price of a given flight, we can interpret coefficients as percentage changes in price. The variables reported in Table 1 are the interaction terms of the LR-ATD (ER-ATD) with the booking day dummy variables (BD). Instead of using a dummy variable for each day of the booking period, we arrange days into 10 booking day subperiods. This allows us to reduce noise and estimate the effect of the LR-ATD (ER-ATD) on prices more efficiently, since scheduling changes, which are necessary for the identification, may not take place on every single day of the booking period. All booking day subperiods consist of 10 days, except from the last subperiod that consists of 6 days (refer to Table 1 for the exact composition of the booking day subperiods). All specifications in Table 1 also include the booking day dummy variables (BD), which implies that the LR-ATD (ER-ATD) interaction coefficients measure the additional effect of competition at a given point in time during the booking period. Finally, we gradually introduce the control variables discussed in Section 3.4. The first specification reports the results of our baseline model (Equation 2), the second specification includes the aircraft type

\footnotetext{
${ }^{23}$ You may refer to Table 6 in the Appendix of this paper for summary statistics on the variables used in the main and robustness analyses.
} 


\begin{tabular}{|c|c|c|c|c|c|c|}
\hline & \multicolumn{2}{|c|}{ (1) } & \multicolumn{2}{|c|}{$(2)$} & \multicolumn{2}{|c|}{ (3) } \\
\hline & LR-ATD & ER-ATD & LR-ATD & ER-ATD & LR-ATD & ER-ATD \\
\hline $95-86$ days & $\begin{array}{c}0.448^{* * *} \\
(0.155)\end{array}$ & $\begin{array}{c}0.406^{* * *} \\
(0.151)\end{array}$ & $\begin{array}{c}0.444^{* * *} \\
(0.154)\end{array}$ & $\begin{array}{c}0.402^{* * *} \\
(0.151)\end{array}$ & $\begin{array}{c}0.460 * * * \\
(0.140)\end{array}$ & $\begin{array}{c}0.408^{* * *} \\
(0.132)\end{array}$ \\
\hline $85-76$ days & $\begin{array}{c}0.462^{* * *} \\
(0.155)\end{array}$ & $\begin{array}{c}0.419^{* * *} \\
(0.152)\end{array}$ & $\begin{array}{c}0.459^{* * *} \\
(0.155)\end{array}$ & $\begin{array}{c}0.416^{* * *} \\
(0.151)\end{array}$ & $\begin{array}{c}0.475^{* * *} \\
(0.141)\end{array}$ & $\begin{array}{c}0.423^{* * *} \\
(0.133)\end{array}$ \\
\hline $75-66$ days & $\begin{array}{c}0.499 * * * \\
(0.153)\end{array}$ & $\begin{array}{c}0.457^{* * *} \\
(0.149)\end{array}$ & $\begin{array}{c}0.496^{* * *} \\
(0.152)\end{array}$ & $\begin{array}{c}0.454^{* * *} \\
(0.149)\end{array}$ & $\begin{array}{c}0.537^{* * *} \\
(0.139)\end{array}$ & $\begin{array}{c}0.487^{* * *} \\
(0.130)\end{array}$ \\
\hline $65-56$ days & $\begin{array}{c}0.525^{* * *} \\
(0.151)\end{array}$ & $\begin{array}{c}0.488^{* * *} \\
(0.147)\end{array}$ & $\begin{array}{c}0.523^{* * *} \\
(0.150)\end{array}$ & $\begin{array}{c}0.487^{* * *} \\
(0.147)\end{array}$ & $\begin{array}{c}0.559^{* * *} \\
(0.138)\end{array}$ & $\begin{array}{c}0.515^{* * *} \\
(0.131)\end{array}$ \\
\hline $55-46$ days & $\begin{array}{c}0.479 * * * \\
(0.150)\end{array}$ & $\begin{array}{c}0.440^{* * *} \\
(0.147)\end{array}$ & $\begin{array}{c}0.476^{* * *} \\
(0.150)\end{array}$ & $\begin{array}{c}0.438^{* * *} \\
(0.147)\end{array}$ & $\begin{array}{c}0.509^{* * *} \\
(0.137)\end{array}$ & $\begin{array}{c}0.469 * * * \\
(0.130)\end{array}$ \\
\hline $45-36$ days & $\begin{array}{c}0.418^{* * *} \\
(0.148)\end{array}$ & $\begin{array}{c}0.380 * * * \\
(0.145)\end{array}$ & $\begin{array}{c}0.415^{* * *} \\
(0.147)\end{array}$ & $\begin{array}{c}0.377^{* * *} \\
(0.144)\end{array}$ & $\begin{array}{c}0.446^{* * *} \\
(0.134)\end{array}$ & $\begin{array}{c}0.406^{* * *} \\
(0.126)\end{array}$ \\
\hline $35-26$ days & $\begin{array}{c}0.373^{* * *} \\
(0.143)\end{array}$ & $\begin{array}{c}0.327^{* *} \\
(0.138)\end{array}$ & $\begin{array}{c}0.370 * * * \\
(0.143)\end{array}$ & $\begin{array}{c}0.324^{* *} \\
(0.137)\end{array}$ & $\begin{array}{c}0.396^{* * *} \\
(0.130)\end{array}$ & $\begin{array}{c}0.345^{* * *} \\
(0.120)\end{array}$ \\
\hline $25-16$ days & $\begin{array}{c}0.316^{* *} \\
(0.149)\end{array}$ & $\begin{array}{l}0.271^{*} \\
(0.148)\end{array}$ & $\begin{array}{c}0.313^{* *} \\
(0.149)\end{array}$ & $\begin{array}{l}0.268^{*} \\
(0.148)\end{array}$ & $\begin{array}{c}0.341^{* *} \\
(0.135)\end{array}$ & $\begin{array}{c}0.290 * * \\
(0.129)\end{array}$ \\
\hline $15-6$ days & $\begin{array}{c}0.175 \\
(0.155)\end{array}$ & $\begin{array}{c}0.149 \\
(0.156)\end{array}$ & $\begin{array}{c}0.172 \\
(0.154)\end{array}$ & $\begin{array}{c}0.146 \\
(0.156)\end{array}$ & $\begin{array}{c}0.212 \\
(0.139)\end{array}$ & $\begin{array}{c}0.183 \\
(0.136)\end{array}$ \\
\hline $6-0$ days & $\begin{array}{l}0.0821 \\
(0.160) \\
\end{array}$ & $\begin{array}{l}0.0740 \\
(0.163) \\
\end{array}$ & $\begin{array}{l}0.0795 \\
(0.160) \\
\end{array}$ & $\begin{array}{l}0.0719 \\
(0.163) \\
\end{array}$ & $\begin{array}{l}0.0636 \\
(0.146) \\
\end{array}$ & $\begin{array}{r}0.0396 \\
(0.143) \\
\end{array}$ \\
\hline Control variables & & & & & & \\
\hline Route-flight FE & Yes & Yes & Yes & Yes & Yes & Yes \\
\hline Aircraft changes & No & No & Yes & Yes & Yes & Yes \\
\hline Fare class & No & No & No & No & Yes & Yes \\
\hline Observations & 220,557 & 220,557 & 220,557 & 220,557 & 220,557 & 220,557 \\
\hline R-Squared & 0.534 & 0.533 & 0.535 & 0.534 & 0.592 & 0.591 \\
\hline Number of flights & 2,338 & 2,338 & 2,338 & 2,338 & 2,338 & 2,338 \\
\hline
\end{tabular}

Table 1 Main results on the effect of competition on dynamic airline pricing. The reported coefficients are interactions of the LR-ATD and ER-ATD with the booking day subperiod dummies. FE denotes the fixed effects. Flight-level clustered standard errors are reported in parentheses. Significance levels are indicated by: ${ }^{* * *} p<0.01,{ }^{* *} p<0.05,{ }^{*} p<0.1$.

fixed effects and the indicators for changes in operating aircraft during the booking period, and the third specification also includes the fare class controls.

The estimated coefficients are similar across specifications for both the LR-ATD 
and the ER-ATD. We therefore use the output of the third specification, which includes all control variables, to interpret the estimated coefficients. The coefficients of the LR-ATD (ER-ATD) interactions are found to be positive and significant in the first 8 booking day subperiods, i.e. until approximately two weeks before departure. This implies that flights facing less competition (higher temporal distance) exhibit higher prices during that period compared to flights facing more competition (lower temporal distance). The coefficients of the last two booking day subperiods are estimated much closer to zero and are not statistically significant, suggesting that prices are similar in the last two weeks before departure irrespective of competition ${ }^{24}$. We interpret these findings as evidence for larger APDs in more competitive settings. The estimated difference in APDs is not only statistically but also economically significant. For example, the estimated coefficient of the LR-ATD between 55 and 46 days before departure is equal to 0.523 . An increase in LR-ATD from 0 (maximum intensity of competition) to 1 (minimum intensity of competition) would thus increase prices by approximately $52 \%$. The normalised LR-ATD with interfirm weighting has a mean of approximately 0.11 and a standard deviation of approximately 0.10 in our sample. A one standard deviation increase in LR-ATD (i.e. decrease in the intensity of competition) would therefore increase listed prices by approximately $5.2 \%$.

The estimated coefficients of the LR-ATD (ER-ATD) interactions exhibit an inverse U-shaped temporal pattern. This can be seen in Figure 5, in which we plot the estimated coefficients of the LR-ATD interactions together with $95 \%$ confidence intervals. The coefficients reach a peak during the fourth booking day subperiod (65-56 days before departure), after which point they start to decrease. This gives rise to non-monotonic temporal profiles of fares for certain values of the LR-ATD (ER-ATD).

\footnotetext{
${ }^{24}$ The included control variables in the second and third specification yield statistically significant coefficients. However, the estimated coefficients for the LR-ATD (ER-ATD) interactions do not significantly differ across specifications. This suggests that scheduling changes are not likely related to changes in aircraft, which could also have an effect on available seats.
} 


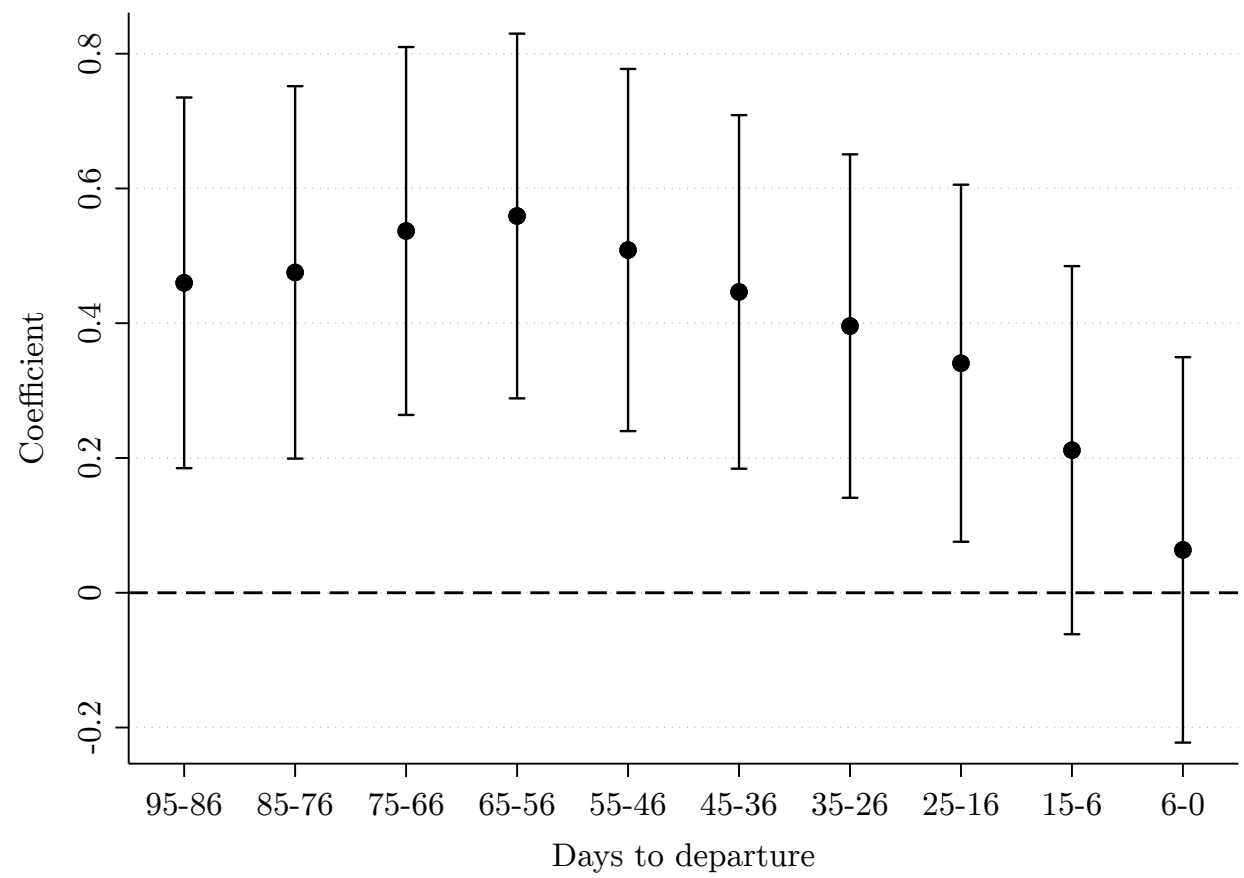

Figure 5 Plot of the estimated coefficients and $95 \%$ confidence intervals for the interaction terms of the LR-ATD with the booking day subperiod dummies.

Figure 6 plots the estimated temporal profile of fares when LR-ATD is 0 (which is equivalent to the baseline temporal profile of fares without the additional effect of competition) and LR-ATD is 1 (minimum intensity of competition). The coefficients are estimated using the first day of the booking period in our dataset as the reference category $^{25}$. The baseline temporal profile of fares we estimate $(\mathrm{LR}$-ATD $=0$ ) is similar to previous empirical literature (Escobari and Gan, 2007; Escobari, 2012; Alderighi et al, 2015); prices are relatively flat at the beginning of the booking period, sharply increase during the final weeks before departure and monotonically increase throughout the booking period. However, the estimated temporal profile of fares for minimum intensity of competition (LR-ATD $=1$ ) is non-monotonic. Prices exhibit a decreasing trend between approximately 60 and 25 days to departure, after which

\footnotetext{
${ }^{25}$ The first day of the booking period is 95 days before the departure date. This means that the estimated coefficients can be interpreted as percentage differences in price with respect to that date.
} 


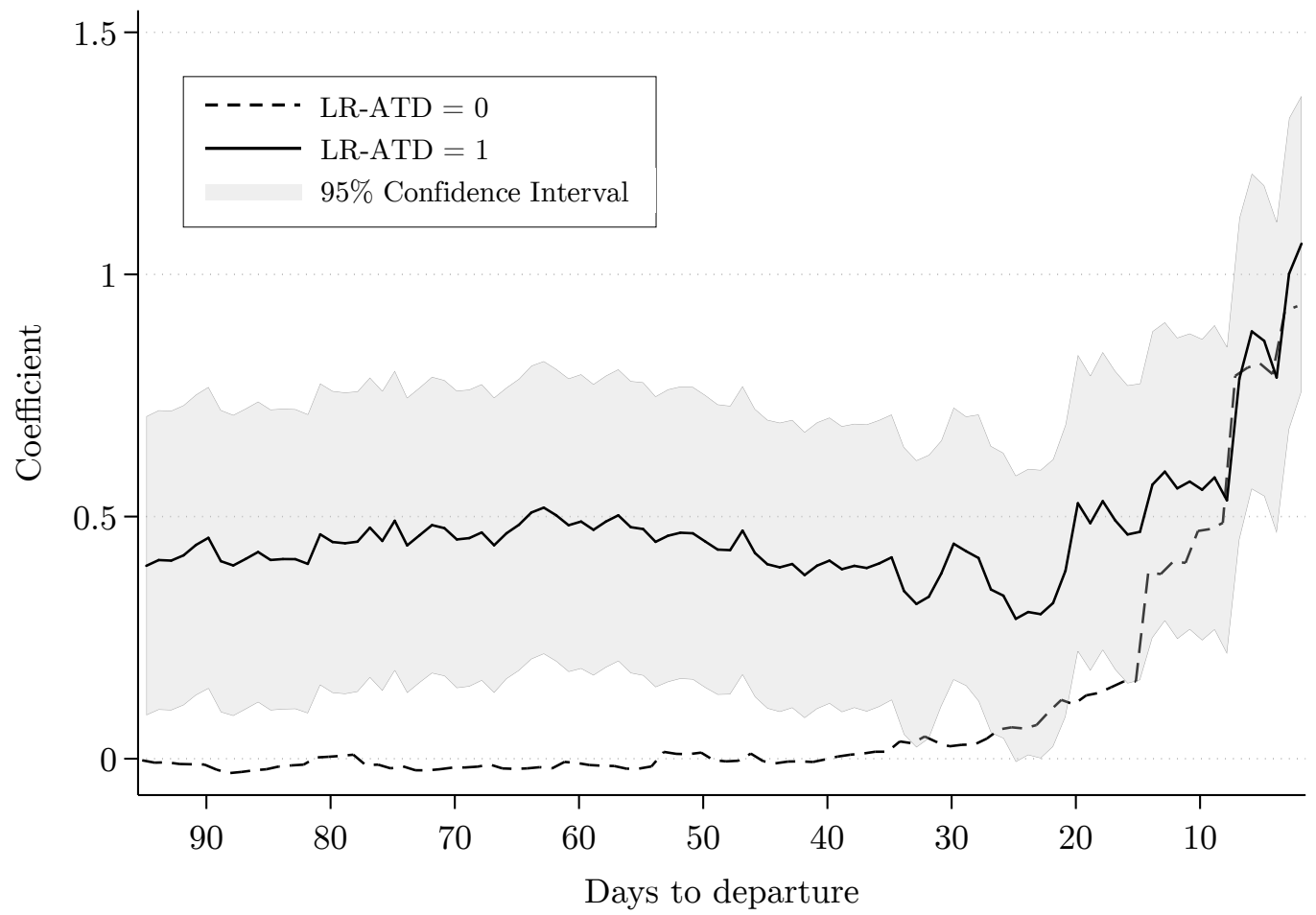

Figure 6 Estimated temporal profile of fares with and without the additional effect of competition. The temporal profile of fares is the result of estimating Equation 2 including the control variables described in Section 3.4. The reference category is the first day of the booking period.

point they begin to (sharply) increase. Similar U-shaped price dynamics are also reported in previous empirical literature on the dynamic pricing of airlines (Escobari and Gan, 2007; Bilotkach et al, 2010; Alderighi et al, 2015).

A decreasing pattern in the dynamic pricing of fares is attributed to the declining option value of unsold seats as the departure date approaches (Gallego and van Ryzin, 1994; Bitran and Mondschein, 1997). This simply reflects the trade-off that airlines face when waiting for customers with a higher willingness to pay but less certain demands at the risk of having unsold seats at the time of departure. Our findings suggest that decreasing patterns in fares are more prominent when the intensity of competition is low. The framework on APDs offers a potential explanation, since firms that offer smaller APDs may also face a greater risk of having unsold seats at the time of departure. This 
would occur if planes fill up slower compared to a situation in which firms compete (by means of larger APDs) to capture consumers with certain demands who are willing to purchase early. Firms offering smaller APDs may therefore have incentives to decrease fares in the middle of the booking period to attract price-sensitive consumers who would not book their flights very early in advance due to high demand uncertainty.

\subsection{Additional analyses}

\subsubsection{Carrier type analysis}

To further explore the effect of competition on dynamic airline pricing and APDs, we run an additional specification that takes into account the type of carrier. We distinguish between two types of carriers, namely legacy carriers (NLCs) and low-cost carriers $(\mathrm{LCCs})^{26}$. NLCs differ from LCCs in many aspects, such as network type and operating cost structure ${ }^{27}$. Previous literature finds significant differences in the strategic behaviour of the two carrier types and the resulting competitive outcomes (e.g., Goolsbee and Syverson, 2008; Brueckner et al, 2013), but has not yet studied the effect of competition on their dynamic pricing strategies ${ }^{28}$. To incorporate the type of carrier in our analysis, we interact the booking day dummy variables and the LR-ATD interactions (i.e. the terms $\mathrm{BD}_{t}$ and $\mathrm{LR}-\mathrm{ATD}_{i k t} \times \mathrm{BD}_{t}$ in Equation 2, respectively) with a dummy variable indicating whether a certain carrier is a low-cost carrier (LCC $=1$ if a carrier is low-cost and 0 otherwise). The temporal profile of fares and the additional

\footnotetext{
${ }^{26}$ The legacy carriers in our sample are: Alaska, American, Delta, Hawaiian, Mokulele and United. The low-cost carriers in our sample are: Frontier, JetBlue, Southwest and Spirit.

${ }^{27}$ Legacy carriers usually operate hub-and-spoke networks, in which one (or multiple) airport hubs are connected to all points in the network (i.e. the spokes) by direct flights. This implies that passengers travelling between two spokes will have to take a connecting flight through the hub. Lowcost carriers usually operate point-to-point networks, in which all points in the network are connected with each other by direct flights.

${ }^{28}$ Alderighi et al (2015) study the effect of capacity utilisation on the dynamic pricing of a European low-cost carrier (Ryanair), but do not have any data on legacy or other low-cost carriers to study potential differences in pricing strategies between the two carrier types.
} 


\begin{tabular}{|c|c|c|c|}
\hline \multirow[b]{2}{*}{ LR-ATD } & \multirow{2}{*}{$\begin{array}{c}(1) \\
\text { All carriers }\end{array}$} & \multicolumn{2}{|c|}{$(2)$} \\
\hline & & Legacy & Low-cost \\
\hline $95-86$ days & $\begin{array}{c}0.460^{* * *} \\
(0.140)\end{array}$ & $\begin{array}{c}0.409 * * * \\
(0.138)\end{array}$ & $\begin{array}{c}0.423 \\
(0.682)\end{array}$ \\
\hline $85-76$ days & $\begin{array}{c}0.475^{* * *} \\
(0.141)\end{array}$ & $\begin{array}{c}0.415^{* * *} \\
(0.138)\end{array}$ & $\begin{array}{c}0.395 \\
(0.676)\end{array}$ \\
\hline $75-66$ days & $\begin{array}{c}0.537^{* * *} \\
(0.139)\end{array}$ & $\begin{array}{c}0.483^{* * *} \\
(0.136)\end{array}$ & $\begin{array}{c}0.366 \\
(0.674)\end{array}$ \\
\hline $65-56$ days & $\begin{array}{c}0.559^{* * *} \\
(0.138)\end{array}$ & $\begin{array}{c}0.507^{* * *} \\
(0.135)\end{array}$ & $\begin{array}{c}0.441 \\
(0.676)\end{array}$ \\
\hline $55-46$ days & $\begin{array}{c}0.509^{* * *} \\
(0.137)\end{array}$ & $\begin{array}{c}0.461^{* * *} \\
(0.134)\end{array}$ & $\begin{array}{c}0.543 \\
(0.684)\end{array}$ \\
\hline $45-36$ days & $\begin{array}{c}0.446^{* * *} \\
(0.134)\end{array}$ & $\begin{array}{c}0.441^{* * *} \\
(0.130)\end{array}$ & $\begin{array}{c}0.543 \\
(0.679)\end{array}$ \\
\hline $35-26$ days & $\begin{array}{c}0.396^{* * *} \\
(0.130)\end{array}$ & $\begin{array}{c}0.440^{* * *} \\
(0.127)\end{array}$ & $\begin{array}{c}0.365 \\
(0.674)\end{array}$ \\
\hline $25-16$ days & $\begin{array}{c}0.341^{* *} \\
(0.135)\end{array}$ & $\begin{array}{c}0.383^{* * *} \\
(0.131)\end{array}$ & $\begin{array}{c}0.597 \\
(0.683)\end{array}$ \\
\hline $15-6$ days & $\begin{array}{c}0.212 \\
(0.139)\end{array}$ & $\begin{array}{l}0.258^{*} \\
(0.136)\end{array}$ & $\begin{array}{c}0.675 \\
(0.641)\end{array}$ \\
\hline $6-0$ days & $\begin{array}{l}0.0636 \\
(0.146) \\
\end{array}$ & $\begin{array}{c}0.104 \\
(0.145) \\
\end{array}$ & $\begin{array}{c}0.804 \\
(0.627)\end{array}$ \\
\hline \multicolumn{4}{|l|}{ Control variables } \\
\hline Route-flight FE & Yes & \multicolumn{2}{|c|}{ Yes } \\
\hline Aircraft changes & Yes & \multicolumn{2}{|c|}{ Yes } \\
\hline Fare class & Yes & \multicolumn{2}{|c|}{ Yes } \\
\hline Observations & 220,557 & \multicolumn{2}{|c|}{220,557} \\
\hline R-Squared & 0.534 & \multicolumn{2}{|c|}{0.606} \\
\hline Number of flights & 2,338 & \multicolumn{2}{|c|}{2,338} \\
\hline
\end{tabular}

Table 2 Carrier type analysis on the effect of competition on dynamic airline pricing. The reported coefficients are interactions of the LR-ATD with the booking day subperiod dummies. FE denotes the fixed effects. Flight-level clustered standard errors are reported in parentheses. Significance levels are indicated by: ${ }^{* * *} p<0.01,{ }^{* *} p<0.05,{ }^{*} p<0.1$.

effect of competition are therefore estimated separately per carrier type. This implies that the LR-ATD interaction coefficients can be interpreted as the additional effect of competition on each carrier type's prices at a given point in time during the booking 
period. The results of the carrier type specification are presented in Table 2. The first column reports the results of our main specification to facilitate comparison, while the second and third column report the estimated coefficients of the LR-ATD interactions for legacy and low-cost carriers, respectively. The estimated coefficients for legacy carriers are similar in direction and magnitude to the results of our main specification, so interpretation remains the same as in Section 4.1. However, the estimated coefficients of the LR-ATD interactions for low-cost carriers are positive but statistically insignificant. The estimated standard errors in the third column are significantly higher compared to the first and second column, which suggests large differences in the employed dynamic pricing strategies of low-cost carriers ${ }^{29}$. Our carrier type analysis thus reveals that the effect of competition on the temporal profile of airline fares and APDs discussed in Section 4.1 is purely driven by the dynamic pricing strategies of legacy carriers.

\subsubsection{Alternative values of $\alpha$ and $\beta$}

As described in Section 3.3, parameters $\alpha$ and $\beta$ measure the extent to which sameday flight departures compete with each other. In our main results, we assume that $\alpha=0.2$ and $\beta=0.5$ to calculate the weights of the LR-ATD and ER-ATD, respectively. We rerun our main specification (Equation 2 including the aircraft-type fixed effects, indicators for changes in aircraft during the booking period and fare class fixed effects) for different values of $\alpha$ and $\beta$ to test the robustness of our main results. The results of those robustness analyses are reported in Tables 3 and 4 . Table 3 reports the LRATD interaction coefficients for $\alpha$ equal to $0.1,0.2$ (main results), 0.3, 0.4 and 0.5 . The specifications in this table yield the same qualitative results as our main analysis. Parameter $\beta_{\in}[0,1]$ is by construction better to use in order to test our assumption

\footnotetext{
${ }^{29}$ In line with previous literature on the Southwest effect (Windle and Dresner, 1995; 1997; Goolsbee and Syverson, 2008), we also run a specification where we separate Southwest from other low-cost carriers. This specification yields the same qualitative results as Table 2.
} 


\begin{tabular}{|c|c|c|c|c|c|}
\hline LR-ATD & $\begin{array}{c}(1) \\
\alpha=0.1\end{array}$ & $\begin{array}{c}(2) \\
\alpha=0.2\end{array}$ & $\begin{array}{c}(3) \\
\alpha=0.3\end{array}$ & $\begin{array}{c}(4) \\
\alpha=0.4\end{array}$ & $\begin{array}{c}(5) \\
\alpha=0.5\end{array}$ \\
\hline $95-86$ days & $\begin{array}{c}0.364^{* *} \\
(0.146)\end{array}$ & $\begin{array}{c}0.460 * * * \\
(0.140)\end{array}$ & $\begin{array}{c}0.389^{* * *} \\
(0.129)\end{array}$ & $\begin{array}{c}0.353^{* * *} \\
(0.122)\end{array}$ & $\begin{array}{c}0.339 * * * \\
(0.115)\end{array}$ \\
\hline $85-76$ days & $\begin{array}{c}0.376^{* *} \\
(0.146)\end{array}$ & $\begin{array}{c}0.475^{* * *} \\
(0.141)\end{array}$ & $\begin{array}{c}0.403^{* * *} \\
(0.130)\end{array}$ & $\begin{array}{c}0.366^{* * *} \\
(0.122)\end{array}$ & $\begin{array}{c}0.351^{* * *} \\
(0.115)\end{array}$ \\
\hline $75-66$ days & $\begin{array}{c}0.427^{* * *} \\
(0.145)\end{array}$ & $\begin{array}{c}0.537^{* * *} \\
(0.139)\end{array}$ & $\begin{array}{c}0.469^{* * *} \\
(0.128)\end{array}$ & $\begin{array}{c}0.432^{* * *} \\
(0.119)\end{array}$ & $\begin{array}{c}0.409 * * * \\
(0.111)\end{array}$ \\
\hline $65-56$ days & $\begin{array}{c}0.450^{* * *} \\
(0.144)\end{array}$ & $\begin{array}{c}0.559^{* * *} \\
(0.138)\end{array}$ & $\begin{array}{c}0.495^{* * *} \\
(0.127)\end{array}$ & $\begin{array}{c}0.457^{* * *} \\
(0.119)\end{array}$ & $\begin{array}{c}0.432^{* * *} \\
(0.112)\end{array}$ \\
\hline $55-46$ days & $\begin{array}{c}0.417^{* * *} \\
(0.143)\end{array}$ & $\begin{array}{c}0.509^{* * *} \\
(0.137)\end{array}$ & $\begin{array}{c}0.443^{* * *} \\
(0.126)\end{array}$ & $\begin{array}{c}0.411^{* * *} \\
(0.118)\end{array}$ & $\begin{array}{c}0.398^{* * *} \\
(0.112)\end{array}$ \\
\hline $45-36$ days & $\begin{array}{c}0.344^{* *} \\
(0.141)\end{array}$ & $\begin{array}{c}0.446^{* * *} \\
(0.134)\end{array}$ & $\begin{array}{c}0.389^{* * *} \\
(0.121)\end{array}$ & $\begin{array}{c}0.366^{* * *} \\
(0.113)\end{array}$ & $\begin{array}{c}0.366^{* * *} \\
(0.107)\end{array}$ \\
\hline $35-26$ days & $\begin{array}{c}0.307^{* *} \\
(0.139)\end{array}$ & $\begin{array}{c}0.396^{* * *} \\
(0.130)\end{array}$ & $\begin{array}{c}0.332^{* * *} \\
(0.115)\end{array}$ & $\begin{array}{c}0.304^{* * *} \\
(0.105)\end{array}$ & $\begin{array}{c}0.298^{* * *} \\
(0.0975)\end{array}$ \\
\hline $25-16$ days & $\begin{array}{l}0.255^{*} \\
(0.142)\end{array}$ & $\begin{array}{c}0.341^{* *} \\
(0.135)\end{array}$ & $\begin{array}{c}0.280^{* *} \\
(0.124)\end{array}$ & $\begin{array}{c}0.255^{* *} \\
(0.117)\end{array}$ & $\begin{array}{c}0.258^{* *} \\
(0.114)\end{array}$ \\
\hline $15-6$ days & $\begin{array}{c}0.230 \\
(0.145)\end{array}$ & $\begin{array}{c}0.212 \\
(0.139)\end{array}$ & $\begin{array}{c}0.146 \\
(0.131)\end{array}$ & $\begin{array}{c}0.143 \\
(0.127)\end{array}$ & $\begin{array}{c}0.168 \\
(0.126)\end{array}$ \\
\hline $6-0$ days & $\begin{array}{c}0.183 \\
(0.148) \\
\end{array}$ & $\begin{array}{l}0.0636 \\
(0.146) \\
\end{array}$ & $\begin{array}{r}-0.0310 \\
(0.139) \\
\end{array}$ & $\begin{array}{r}-0.0313 \\
(0.136) \\
\end{array}$ & $\begin{array}{c}0.000808 \\
(0.135) \\
\end{array}$ \\
\hline \multicolumn{6}{|l|}{ Control variables } \\
\hline Route-flight FE & Yes & Yes & Yes & Yes & Yes \\
\hline Aircraft changes & Yes & Yes & Yes & Yes & Yes \\
\hline Fare class & Yes & Yes & Yes & Yes & Yes \\
\hline Observations & 220,557 & 220,557 & 220,557 & 220,557 & 220,557 \\
\hline R-Squared & 0.591 & 0.592 & 0.591 & 0.591 & 0.590 \\
\hline Number of flights & 2,338 & 2,338 & 2,338 & 2,338 & 2,338 \\
\hline
\end{tabular}

Table 3 Robustness analyses of the main specification for different values of $\alpha$. The reported coefficients are interactions of the LR-ATD with the booking day subperiod dummies. FE denotes the fixed effects. Flight-level clustered standard errors are reported in parentheses. Significance levels are indicated by: ${ }^{* * *} p<0.01,{ }^{* *} p<0.05, * p<0.1$.

that all same-day flight departures are not likely to compete in the same way ${ }^{30}$. We

\footnotetext{
${ }^{30}$ Note that for $\alpha \geq 0.5$ flights with a rank $r \geq 2$ will all receive zero weight in the calculation of the LR-ATD. The calculated LR-ATDs are thus similar above that value of $\alpha$, which is not a problem when using the exponential weight $\beta$.
} 


\begin{tabular}{|c|c|c|c|c|c|}
\hline ER-ATD & $\begin{array}{c}(1) \\
\beta=0.2\end{array}$ & $\begin{array}{c}(2) \\
\beta=0.4\end{array}$ & $\begin{array}{c}(3) \\
\beta=0.5\end{array}$ & $\begin{array}{c}(4) \\
\beta=0.6\end{array}$ & $\begin{array}{c}(5) \\
\beta=0.8\end{array}$ \\
\hline $95-86$ days & $\begin{array}{c}0.318^{* * *} \\
(0.108)\end{array}$ & $\begin{array}{c}0.387^{* * *} \\
(0.125)\end{array}$ & $\begin{array}{c}0.408^{* * *} \\
(0.132)\end{array}$ & $\begin{array}{c}0.403^{* * *} \\
(0.138)\end{array}$ & $\begin{array}{c}0.212 \\
(0.143)\end{array}$ \\
\hline $85-76$ days & $\begin{array}{c}0.331^{* * *} \\
(0.108)\end{array}$ & $\begin{array}{c}0.403^{* * *} \\
(0.125)\end{array}$ & $\begin{array}{c}0.423^{* * *} \\
(0.133)\end{array}$ & $\begin{array}{c}0.417^{* * *} \\
(0.139)\end{array}$ & $\begin{array}{c}0.213 \\
(0.144)\end{array}$ \\
\hline 75 - 66 days & $\begin{array}{c}0.380^{* * *} \\
(0.105)\end{array}$ & $\begin{array}{c}0.465^{* * *} \\
(0.123)\end{array}$ & $\begin{array}{c}0.487^{* * *} \\
(0.130)\end{array}$ & $\begin{array}{c}0.480 * * * \\
(0.137)\end{array}$ & $\begin{array}{l}0.265^{*} \\
(0.142)\end{array}$ \\
\hline $65-56$ days & $\begin{array}{c}0.404^{* * *} \\
(0.106)\end{array}$ & $\begin{array}{c}0.493^{* * *} \\
(0.124)\end{array}$ & $\begin{array}{c}0.515^{* * *} \\
(0.131)\end{array}$ & $\begin{array}{c}0.508^{* * *} \\
(0.136)\end{array}$ & $\begin{array}{c}0.297^{* *} \\
(0.142)\end{array}$ \\
\hline $55-46$ days & $\begin{array}{c}0.371^{* * *} \\
(0.107)\end{array}$ & $\begin{array}{c}0.448^{* * *} \\
(0.123)\end{array}$ & $\begin{array}{c}0.469^{* * *} \\
(0.130)\end{array}$ & $\begin{array}{c}0.463^{* * *} \\
(0.135)\end{array}$ & $\begin{array}{l}0.267^{*} \\
(0.140)\end{array}$ \\
\hline 45 - 36 days & $\begin{array}{c}0.346^{* * *} \\
(0.104)\end{array}$ & $\begin{array}{c}0.396^{* * *} \\
(0.119)\end{array}$ & $\begin{array}{c}0.406^{* * *} \\
(0.126)\end{array}$ & $\begin{array}{c}0.393^{* * *} \\
(0.132)\end{array}$ & $\begin{array}{c}0.193 \\
(0.138)\end{array}$ \\
\hline $35-26$ days & $\begin{array}{c}0.276^{* * *} \\
(0.0946)\end{array}$ & $\begin{array}{c}0.330^{* * *} \\
(0.112)\end{array}$ & $\begin{array}{c}0.345^{* * *} \\
(0.120)\end{array}$ & $\begin{array}{c}0.340^{* * *} \\
(0.127)\end{array}$ & $\begin{array}{c}0.169 \\
(0.135)\end{array}$ \\
\hline $25-16$ days & $\begin{array}{c}0.239^{* *} \\
(0.112)\end{array}$ & $\begin{array}{c}0.279 * * \\
(0.124)\end{array}$ & $\begin{array}{c}0.290^{* *} \\
(0.129)\end{array}$ & $\begin{array}{c}0.283^{* *} \\
(0.134)\end{array}$ & $\begin{array}{c}0.128 \\
(0.139)\end{array}$ \\
\hline $15-6$ days & $\begin{array}{c}0.146 \\
(0.124)\end{array}$ & $\begin{array}{c}0.165 \\
(0.132)\end{array}$ & $\begin{array}{c}0.183 \\
(0.136)\end{array}$ & $\begin{array}{c}0.200 \\
(0.139)\end{array}$ & $\begin{array}{c}0.144 \\
(0.143)\end{array}$ \\
\hline $6-0$ days & $\begin{array}{r}-0.0163 \\
(0.133) \\
\end{array}$ & $\begin{array}{c}0.00324 \\
(0.140) \\
\end{array}$ & $\begin{array}{r}0.0396 \\
(0.143) \\
\end{array}$ & $\begin{array}{l}0.0869 \\
(0.146) \\
\end{array}$ & $\begin{array}{c}0.145 \\
(0.148) \\
\end{array}$ \\
\hline \multicolumn{6}{|l|}{ Control variables } \\
\hline Route-flight FE & Yes & Yes & Yes & Yes & Yes \\
\hline Aircraft changes & Yes & Yes & Yes & Yes & Yes \\
\hline Fare class & Yes & Yes & Yes & Yes & Yes \\
\hline Observations & 220,557 & 220,557 & 220,557 & 220,557 & 220,557 \\
\hline R-Squared & 0.591 & 0.591 & 0.591 & 0.591 & 0.591 \\
\hline Number of flights & 2,338 & 2,338 & 2,338 & 2,338 & 2,338 \\
\hline
\end{tabular}

Table 4 Robustness analyses of the main specification for different values of $\beta$. The reported coefficients are interactions of the ER-ATD with the booking day subperiod dummies. FE denotes the fixed effects. Flight-level clustered standard errors are reported in parentheses. Significance levels are indicated by: ${ }^{* * *} p<0.01,{ }^{* *} p<0.05,{ }^{*} p<0.1$.

rerun the main specification and let $\beta$ approach 1 , which would imply that all sameday flight departures receive the same weight in the calculation of the average temporal distance and are therefore assumed to compete equally. Table 4 reports the ER-ATD 
interaction coefficients for $\beta$ equal to $0.2,0.4,0.5$ (main results), 0.6 and 0.8 . For $\beta<0.8$ we find the same qualitative results as in our main analysis ${ }^{31}$. For $\beta \geq 0.8$, the estimated coefficients of the ER-ATD interactions are significantly lower in magnitude and are found to be statistically insignificant. This confirms our expectation that same-day flight departures are not likely to be competing equally and that weights that prioritise direct neighbours in the calculation of the average are important in order to measure the intensity of competition correctly ${ }^{32}$.

\subsubsection{Alternative departure dates}

We collect booking period data for two more departure dates and replicate our main analysis to check the robustness of the main results. The data for the additional departure dates was also collected using the procedure that is described in Section 3.1. The additional departure dates are Monday, January $28^{\text {th }}, 2019$ and Thursday, January $31^{\text {st }}, 2019$. These dates were selected so that they do not coincide with (or are close to) any public holidays or other significant events, which is also the case with the departure date in our main analysis, Monday, October $22^{\text {nd }}$, 2018. The LR-ATD (ER-ATD) interaction coefficients from the different departure date specifications are reported in Table 5. All specifications yield the same qualitative results. These results are also similar to the ones in our main analysis. The main difference with respect to the effect of competition on APDs is that the LR-ATD (ER-ATD) interactions in the specifications

\footnotetext{
${ }^{31}$ The estimated coefficients for $\beta \leq 0.2$ are smaller in magnitude compared to the results of our main specification with $\beta=0.5$, but still significantly different from 0 . As $\beta$ is approaching 0 , direct neighbours in departure time become increasingly more important in the calculation of the average. In the extreme case when $\beta=0$, all competing flights with a different departure time receive zero weight irrespective of their distance to a given flight. Flights are thus assumed to be competing only with other flights departing at the exact same time during the day. This underestimates the true intensity of competition, which likely explains why the estimated coefficients of the ER-ATD interactions are smaller in magnitude.

${ }^{32}$ The estimated coefficient of the ER-ATD interaction with the fourth booking day subperiod (6556 days before departure) is the only coefficient that is statistically significant at the $5 \%$ level for $\beta=0.8$. The estimated coefficients of the ER-ATD interactions for $\beta=0.9$ are found to be much closer to 0 and are all statistically insignificant.
} 


\begin{tabular}{|c|c|c|c|c|}
\hline & \multicolumn{2}{|c|}{ 28th January 2019} & \multicolumn{2}{|c|}{ 31st January 2019} \\
\hline & LR-ATD & ER-ATD & LR-ATD & ER-ATD \\
\hline \multirow[t]{2}{*}{$95-86$ days } & $0.719^{* *}$ & $0.478^{*}$ & $0.665^{* * *}$ & $0.499^{* * *}$ \\
\hline & $(0.296)$ & $(0.260)$ & $(0.159)$ & $(0.174)$ \\
\hline \multirow[t]{2}{*}{85 - 76 days } & $0.791^{* * *}$ & $0.576^{* *}$ & $0.593^{* * *}$ & $0.415^{* *}$ \\
\hline & $(0.298)$ & $(0.263)$ & $(0.159)$ & $(0.174)$ \\
\hline \multirow[t]{2}{*}{$75-66$ days } & $0.770 * * *$ & $0.546^{* *}$ & $0.535^{* * *}$ & $0.336^{*}$ \\
\hline & $(0.298)$ & $(0.264)$ & $(0.159)$ & $(0.174)$ \\
\hline \multirow[t]{2}{*}{$65-56$ days } & $0.805^{* * *}$ & $0.595^{* *}$ & $0.594^{* * *}$ & $0.413^{* *}$ \\
\hline & $(0.298)$ & $(0.263)$ & $(0.157)$ & $(0.170)$ \\
\hline \multirow[t]{2}{*}{$55-46$ days } & $0.832^{* * *}$ & $0.631^{* *}$ & $0.624^{* * *}$ & $0.451^{* * *}$ \\
\hline & $(0.297)$ & $(0.261)$ & $(0.156)$ & $(0.168)$ \\
\hline \multirow[t]{2}{*}{$45-36$ days } & $0.775^{* * *}$ & $0.555^{* *}$ & $0.701^{* * *}$ & $0.540^{* * *}$ \\
\hline & $(0.297)$ & $(0.262)$ & $(0.157)$ & $(0.168)$ \\
\hline \multirow[t]{2}{*}{$35-26$ days } & $0.855^{* * *}$ & $0.646^{* *}$ & $0.837^{* * *}$ & $0.697^{* * *}$ \\
\hline & $(0.298)$ & $(0.265)$ & $(0.158)$ & $(0.171)$ \\
\hline \multirow[t]{2}{*}{$25-16$ days } & $0.983^{* * *}$ & $0.804^{* * *}$ & $0.931^{* * *}$ & $0.823^{* * *}$ \\
\hline & $(0.299)$ & $(0.267)$ & $(0.155)$ & $(0.167)$ \\
\hline \multirow[t]{2}{*}{$15-6$ days } & $0.772^{* * *}$ & $0.571^{* *}$ & $0.712^{* * *}$ & $0.571^{* * *}$ \\
\hline & $(0.293)$ & $(0.258)$ & $(0.150)$ & $(0.161)$ \\
\hline \multirow[t]{2}{*}{$6-0$ days } & 0.175 & -0.114 & 0.178 & -0.0388 \\
\hline & $(0.280)$ & $(0.239)$ & $(0.134)$ & $(0.133)$ \\
\hline \multicolumn{5}{|l|}{ Control variables } \\
\hline Route-flight FE & Yes & Yes & Yes & Yes \\
\hline Aircraft changes & Yes & Yes & Yes & Yes \\
\hline Fare class & Yes & Yes & Yes & Yes \\
\hline Observations & 196,954 & 196,954 & 196,359 & 196,359 \\
\hline R-Squared & 0.587 & 0.587 & 0.535 & 0.535 \\
\hline Number of flights & 2,219 & 2,219 & 2,215 & 2,215 \\
\hline
\end{tabular}

Table 5 Robustness analyses of the main specification for different departure dates. The reported coefficients are interactions of the LR-ATD and ER-ATD with the booking day subperiod dummies. FE denotes the fixed effects. Flight-level clustered standard errors are reported in parentheses. Significance levels are indicated by: ${ }^{* * *} p<0.01,{ }^{* *} p<0.05,{ }^{*} p<0.1$.

in Table 5 are positive and significant up until the $9^{\text {th }}$ booking day subperiod, i.e. approximately a week before departure (in contrast to approximately two weeks before departure in our main analysis). The estimated coefficients are comparable in relative 
magnitude to the ones in our main analysis. The reason that the coefficients are estimated larger in absolute terms is that the LR-ATD (ER-ATD) has a smaller range in the two additional samples (refer to Table 6 in the Appendix of this paper for summary statistics). Furthermore, changes in flight departures, which is the source of our identification, are also smaller in these samples. In the samples of Monday, January $28^{\text {th }}, 2019$ and Thursday, January $31^{\text {st }}$, 2019, changes in departure time are approximately 10 minutes on average (15 minutes in the main sample) and $95 \%$ of those departure time changes is less or equal to 35 minutes (1 hour in the main sample).

\section{Conclusion}

This paper builds on the extensive theoretical literature on APDs in the dynamic pricing of perishable goods under demand uncertainty to test the hypothesis that the discounts offered by firms increase with the intensity of competition. Both the descriptive and econometric evidence from a sample of airline fare quotes provide strong support for this theoretical prediction. Flights facing more competition consistently exhibit lower prices than flights facing less competition in the period from about 3 months to 2 weeks before the flight departure. In the final two weeks before departure, prices are similar regardless of the intensity of competition. The effect of competition on APDs is economically significant; airline fare quotes increase by approximately $5.2 \%$ for a one standard deviation decrease in the intensity of competition based on our measure of temporal proximity to rivals. This indicates that competition is an important determinant of the temporal profile of airline fares. Our carrier-type analysis suggests that these results are likely driven by the dynamic pricing of legacy carriers. There is insufficient econometric evidence to conclude that competition also has an effect on the temporal profile of fares of low-cost carriers. 
Our results suggest that airline price dispersion increases with the intensity of competition. Price dispersion is greater when there is more competition because fares decrease at the beginning of the booking period (due to larger APDs), while fares towards the end of the booking period remain the same. We therefore find no evidence of firms extracting more surplus from consumers with more inelastic demands (last-minute bookers) when there is less competition, which would be the prediction of textbook theory on price discrimination. These findings suggest that the analysis of the effect of competition on airline price discrimination is incomplete without considering the intertemporal dimension and APDs. This may explain the mixed results in previous literature on airline price dispersion that has studied the effect of competition by using average price data (Borenstein and Rose, 1994; Stavins, 2001; Gerardi and Shapiro, 2009; Dai et al, 2014).

A practical implication that follows from our analysis is that the relative position of flights with respect to competitors can have significant impact on the employed dynamic pricing strategies. Flights that are relatively far from competitors are likely to enjoy some benefits from being alone, which are reflected by the premium these firms are able to charge during the beginning of the booking period. Although the location of flights is predetermined in our analysis, airlines are able to choose their departure times to a certain extent in the long term. Our results therefore highlight the importance of taking into account the relative proximity of flights to competition during the slot allocation process. Our average temporal distance measure may assist in keeping that in check. This is especially important in settings where carriers could potentially exercise a lot of influence to secure a favourable outcome, such as their hubs or airports in which their presence is dominant.

Despite the potential benefits for airlines from the lack of competition, the effect on total welfare is difficult to determine in this setting. For example, Möller and Watanabe 
(2016) show that the aggregate effect of competition can also be negative under certain conditions in an oligopolistic setting, due to a mismatch between consumer preferences and product characteristics (i.e. consumers having to make purchases without full knowledge of their preferences). Drawing conclusions with respect to total welfare is thus out of the scope of this paper and is left for future research.

\section{Appendix}

Table 6 presents summary statistics for the standardised LR-ATD and ER-ATD with interfirm weighting used in the main and robustness analyses. Table 7 describes the routes (origin and destination airport pairs) for which the data was collected. These are the 100 biggest U.S. domestic routes based on the number of yearly transported passengers in 2017, as reported by the Bureau of Transportation Statistics (BTS). The routes are presented in order of size.

\begin{tabular}{lcccc}
\hline & Mean & St. dev. & Min & Max \\
\hline LR-ATD & & & & \\
\hline $22^{\text {nd }}$ October 2018 & 0.109 & 0.102 & 0 & 1 \\
$28^{\text {th }}$ January 2019 & 0.092 & 0.088 & 0 & 1 \\
$31^{\text {st }}$ January 2019 & 0.095 & 0.092 & 0 & 1 \\
\hline ER-ATD & & & & \\
\hline $22^{\text {nd }}$ October 2018 & 0.095 & 0.087 & 0 & 1 \\
$28^{\text {th }}$ January 2019 & 0.076 & 0.070 & 0 & 1 \\
$31^{\text {st }}$ January 2019 & 0.079 & 0.074 & 0 & 1 \\
\hline
\end{tabular}

Table 6 Summary statistics for the standardised LR-ATD and ER-ATD with interfirm weighting used in the main analysis with departure date the $22^{\text {nd }}$ of October 2018 and the robustness analyses with departure dates the $28^{\text {th }}$ and $31^{\text {st }}$ of January 2019. 


\begin{tabular}{|c|c|c|}
\hline & Origin airport & Destination airport \\
\hline 1. & Los Angeles International (LAX) & San Francisco International (SFO) \\
\hline 2 . & San Francisco International (SFO) & Los Angeles International (LAX) \\
\hline 3. & Los Angeles International (LAX) & New York John F. Kennedy (JFK) \\
\hline 4. & New York John F. Kennedy (JFK) & Los Angeles International (LAX) \\
\hline 5 & New York LaGuardia (LGA) & Chicago O'Hare International (ORD) \\
\hline 6. & Chicago O'Hare International (ORD) & New York LaGuardia (LGA) \\
\hline 7. & Los Angeles International (LAX) & Chicago O'Hare International (ORD) \\
\hline 8. & Chicago O'Hare International (ORD) & Los Angeles International (LAX) \\
\hline 9. & Las Vegas International (LAS) & Los Angeles International (LAX) \\
\hline 10. & Los Angeles International (LAX) & Seattle-Tacoma International (SEA) \\
\hline 11. & Orlando International (MCO) & Atlanta Hartsfield-Jackson (ATL) \\
\hline 12. & Atlanta Hartsfield-Jackson (ATL) & Orlando International (MCO) \\
\hline 13. & Seattle-Tacoma International (SEA) & Los Angeles International (LAX) \\
\hline 14. & Los Angeles International (LAX) & Las Vegas International (LAS) \\
\hline 15. & Denver International (DEN) & Los Angeles International (LAX) \\
\hline 16. & Los Angeles International (LAX) & Denver International (DEN) \\
\hline 17. & San Francisco International (SFO) & Chicago O'Hare International (ORD) \\
\hline 18. & Fort Lauderdale Hollywood (FLL) & Atlanta Hartsfield-Jackson (ATL) \\
\hline 19. & Chicago O'Hare International (ORD) & San Francisco International (SFO) \\
\hline 20. & Atlanta Hartsfield-Jackson (ATL) & New York LaGuardia (LGA) \\
\hline 21. & New York LaGuardia (LGA) & Atlanta Hartsfield-Jackson (ATL) \\
\hline 22. & Atlanta Hartsfield-Jackson (ATL) & Fort Lauderdale Hollywood (FLL) \\
\hline 23. & Seattle-Tacoma International (SEA) & San Francisco International (SFO) \\
\hline 24. & San Francisco International (SFO) & Seattle-Tacoma International (SEA) \\
\hline 25. & Atlanta Hartsfield-Jackson (ATL) & Los Angeles International (LAX) \\
\hline 26. & Los Angeles International (LAX) & Atlanta Hartsfield-Jackson (ATL) \\
\hline 27. & Las Vegas International (LAS) & San Francisco International (SFO) \\
\hline 28. & Honolulu International (HNL) & Los Angeles International (LAX) \\
\hline 29. & Los Angeles International (LAX) & Honolulu International (HNL) \\
\hline 30. & San Francisco International (SFO) & Las Vegas International (LAS) \\
\hline 31. & Denver International (DEN) & Phoenix International (PHX) \\
\hline 32. & Dallas Fort Worth (DFW) & Los Angeles International (LAX) \\
\hline 33. & Tampa International (TPA) & Atlanta Hartsfield-Jackson (ATL) \\
\hline 34. & Phoenix International (PHX) & Denver International (DEN) \\
\hline 35. & Los Angeles International (LAX) & Dallas Fort Worth (DFW) \\
\hline 36. & Denver International (DEN) & San Francisco International (SFO) \\
\hline 37. & Atlanta Hartsfield-Jackson (ATL) & Tampa International (TPA) \\
\hline 38. & New York John F. Kennedy (JFK) & San Francisco International (SFO) \\
\hline 39. & San Francisco International (SFO) & New York John F. Kennedy (JFK) \\
\hline 40. & Kahului Airport (OGG) & Honolulu International (HNL) \\
\hline
\end{tabular}




\begin{tabular}{|c|c|c|}
\hline & Origin airport & Destination airport \\
\hline 41. & New York Newark (EWR) & Orlando International (MCO) \\
\hline 42. & Honolulu International (HNL) & Kahului Airport (OGG) \\
\hline 43. & Denver International (DEN) & Las Vegas International (LAS) \\
\hline 44. & Chicago O'Hare International (ORD) & Denver International (DEN) \\
\hline 45. & Dallas Fort Worth (DFW) & Chicago O'Hare International (ORD) \\
\hline 46. & Orlando International (MCO) & New York Newark (EWR) \\
\hline 47. & Las Vegas International (LAS) & Denver International (DEN) \\
\hline 48. & San Francisco International (SFO) & Denver International (DEN) \\
\hline 49. & Chicago O'Hare International (ORD) & Dallas Fort Worth (DFW) \\
\hline 50. & Denver International (DEN) & Chicago O'Hare International (ORD) \\
\hline 51. & San Francisco International (SFO) & New York Newark (EWR) \\
\hline 52. & Seattle-Tacoma International (SEA) & Anchorage Ted Stevens (ANC) \\
\hline 53. & Chicago O'Hare International (ORD) & Boston Logan International (BOS) \\
\hline 54. & Anchorage Ted Stevens (ANC) & Seattle-Tacoma International (SEA) \\
\hline 55. & Atlanta Hartsfield-Jackson (ATL) & Boston Logan International (BOS) \\
\hline 56. & Boston Logan International (BOS) & Chicago O'Hare International (ORD) \\
\hline 57. & New York Newark (EWR) & San Francisco International (SFO) \\
\hline 58. & Boston Logan International (BOS) & Atlanta Hartsfield-Jackson (ATL) \\
\hline 59. & Chicago O'Hare International (ORD) & Minneapolis Saint Paul (MSP) \\
\hline 60. & Minneapolis Saint Paul (MSP) & Chicago O'Hare International (ORD) \\
\hline 61. & Atlanta Hartsfield-Jackson (ATL) & Washington National (DCA) \\
\hline 62. & Denver International (DEN) & Seattle-Tacoma International (SEA) \\
\hline 63. & Washington National (DCA) & Atlanta Hartsfield-Jackson (ATL) \\
\hline 64. & Seattle-Tacoma International (SEA) & Denver International (DEN) \\
\hline 65. & Chicago O'Hare International (ORD) & Atlanta Hartsfield-Jackson (ATL) \\
\hline 66. & Atlanta Hartsfield-Jackson (ATL) & Dallas Fort Worth (DFW) \\
\hline 67. & Atlanta Hartsfield-Jackson (ATL) & Chicago O'Hare International (ORD) \\
\hline 68. & Dallas Fort Worth (DFW) & Atlanta Hartsfield-Jackson (ATL) \\
\hline 69 & Atlanta Hartsfield-Jackson (ATL) & Denver International (DEN) \\
\hline 70. & San Diego International (SAN) & San Francisco International (SFO) \\
\hline 71. & Las Vegas International (LAS) & Seattle-Tacoma International (SEA) \\
\hline 72. & San Francisco International (SFO) & San Diego International (SAN) \\
\hline 73. & Salt Lake City International (SLC) & Denver International (DEN) \\
\hline 74. & Denver International (DEN) & Atlanta Hartsfield-Jackson (ATL) \\
\hline 75. & Minneapolis Saint Paul (MSP) & Denver International (DEN) \\
\hline 76. & Fort Lauderdale Hollywood (FLL) & New York Newark (EWR) \\
\hline 77. & Seattle-Tacoma International (SEA) & Las Vegas International (LAS) \\
\hline 78. & Denver International (DEN) & Minneapolis Saint Paul (MSP) \\
\hline 79. & New York Newark (EWR) & Fort Lauderdale Hollywood (FLL) \\
\hline 80. & Phoenix International (PHX) & Los Angeles International (LAX) \\
\hline
\end{tabular}




\begin{tabular}{lll}
\hline & Origin airport & Destination airport \\
\hline 81. & Atlanta Hartsfield-Jackson (ATL) & Baltimore Washington (BWI) \\
82. & Los Angeles International (LAX) & New York Newark (EWR) \\
83. & Baltimore Washington (BWI) & Atlanta Hartsfield-Jackson (ATL) \\
84. & Denver International (DEN) & Dallas Fort Worth (DFW) \\
85. & Dallas Fort Worth (DFW) & Denver International (DEN) \\
86. & Los Angeles International (LAX) & Phoenix International (PHX) \\
87. & Denver International (DEN) & Salt Lake City International (SLC) \\
88. & Miami International (MIA) & New York LaGuardia (LGA) \\
89. & Phoenix International (PHX) & Chicago O'Hare International (ORD) \\
90. & Chicago O'Hare International (ORD) & Phoenix International (PHX) \\
91. & Phoenix International (PHX) & Seattle-Tacoma International (SEA) \\
92. & Atlanta Hartsfield-Jackson (ATL) & Detroit Metropolitan (DTW) \\
93. & Seattle-Tacoma International (SEA) & Phoenix International (PHX) \\
94. & New York LaGuardia (LGA) & Miami International (MIA) \\
95. & New York Newark (EWR) & Los Angeles International (LAX) \\
96. & Detroit Metropolitan (DTW) & Atlanta Hartsfield-Jackson (ATL) \\
97. & Atlanta Hartsfield-Jackson (ATL) & Philadelphia International (PHL) \\
98. & Chicago O'Hare International (ORD) & Washington National (DCA) \\
99. & Philadelphia International (PHL) & Atlanta Hartsfield-Jackson (ATL) \\
100. & Washington National (DCA) & Chicago O'Hare International (ORD) \\
\hline
\end{tabular}

Table 7 Description of the routes (origin and destination airport pairs) for which the data was collected. These are the 100 biggest U.S. domestic routes based on the number of yearly transported passengers in 2017, as reported by the Bureau of Transportation Statistics (BTS). The routes are presented in order of size. These routes capture a significant share of the U.S. domestic market, comprising approximately $40 \%$ of the total passengers transported in 2017. 


\section{References}

Aghion, P., Harris, C., and Vickers, J. (1997). Competition and growth with step-bystep innovation: An example. European Economic Review, 41(3-5), 771-782.

Alderighi, M., Nicolini, M., and Piga, C. A. (2015). Combined effects of capacity and time on fares: insights from the yield management of a low-cost airline. Review of Economics and Statistics, 97(4), 900-915.

Anderson, S. (1987). Spatial competition and price leadership. International Journal of Industrial Organization, 5(4), 369-398.

Arrow, K. J. (1962). Economic welfare and the allocation of resources for invention. In Readings in industrial economics, Palgrave, London.

d'Aspremont, C., Gabszewicz, J. J., and Thisse, J. F. (1979). On Hotelling's" Stability in competition". Econometrica, 1145-1150.

Bester, H., and Petrakis, E. (1993). The incentives for cost reduction in a differentiated industry. International Journal of Industrial Organization, 11(4), 519-534.

Bilotkach, V., Gorodnichenko, Y., and Talavera, O. (2010). Are airlines' price-setting strategies different?. Journal of Air Transport Management, 16(1), 1-6.

Bitran, G. R., and Mondschein, S. V. (1997). Periodic pricing of seasonal products in retailing. Management Science, 43(1), 64-79.

Bonanno, G., and Haworth, B. (1998). Intensity of competition and the choice between product and process innovation. International Journal of Industrial Organization, 16(4), 495-510.

Boone, J. (2000). Competitive pressure: the effects on investments in product and process innovation. RAND Journal of Economics, 549-569.

Boone, J. (2001). Intensity of competition and the incentive to innovate. International Journal of Industrial Organization, 19(5), 705-726.

Borenstein, S., and Rose, N. L. (1994). Competition and price dispersion in the US airline industry. Journal of Political Economy, 102(4), 653-683.

Borenstein, S., and Netz, J. (1999). Why do all the flights leave at 8 am?: Competition and departure-time differentiation in airline markets. International Journal of Industrial Organization, 17(5), 611-640.

Brueckner, J. K., Lee, D., and Singer, E. S. (2013). Airline competition and domestic US airfares: A comprehensive reappraisal. Economics of Transportation, 2(1), 1-17. 
Dai, M., Liu, Q., and Serfes, K. (2014). Is the effect of competition on price dispersion nonmonotonic? Evidence from the US airline industry. Review of Economics and Statistics, 96(1), 161-170.

Dana, Jr, J. D. (1998). Advance-purchase discounts and price discrimination in competitive markets. Journal of Political Economy, 106(2), 395-422.

Dana Jr, J. D. (1999). Equilibrium price dispersion under demand uncertainty: the roles of costly capacity and market structure. RAND Journal of Economics, 632660 .

Dana, J. D. J. (2001). Monopoly price dispersion under demand uncertainty. International Economic Review, 42(3), 649-670.

Delbono, F., and Denicolò, V. (1990). R\&D investment in a symmetric and homogeneous oligopoly: Bertrand vs Cournot. International Journal of Industrial Organization, 8(2), 297-313.

Deneckere, R., and Peck, J. (2012). Dynamic competition with random demand and costless search: A theory of price posting. Econometrica, 80(3), 1185-1247.

Douglas, G. W., and Miller, J. C. (1974). Economic Regulation of Domestic Air Transport: Theory and Policy. The Brookings Institution, Washington, DC.

Eaton, B. C., and Lipsey, R. G. (1976). The non-uniqueness of equilibrium in the Loschian location model. American Economic Review, 66(1), 77-93.

Eden, B. (1990). Marginal cost pricing when spot markets are complete. Journal of Political Economy, 98(6), 1293-1306.

Escobari, D., and Gan, L. (2007). Price dispersion under costly capacity and demand uncertainty (No. w13075). National Bureau of Economic Research.

Escobari, D. (2012). Dynamic pricing, advance sales and aggregate demand learning in airlines. Journal of Industrial Economics, 60(4), 697-724.

Gaggero, A. A., and Piga, C. A. (2011). Airline market power and intertemporal price dispersion. Journal of Industrial Economics, 59(4), 552-577.

Gale, I. (1993). Price dispersion in a market with advance-purchases. Review of Industrial Organization, 8(4), 451-464.

Gale, I. L., and Holmes, T. J. (1992). The efficiency of advance-purchase discounts in the presence of aggregate demand uncertainty. International Journal of Industrial Organization, 10(3), 413-437.

Gale, I. L., and Holmes, T. J. (1993). Advance-purchase discounts and monopoly allocation of capacity. American Economic Review, 135-146. 
Gallego, G., and Hu, M. (2014). Dynamic pricing of perishable assets under competition. Management Science, 60(5), 1241-1259.

Gallego, G., and Van Ryzin, G. (1994). Optimal dynamic pricing of inventories with stochastic demand over finite horizons. Management Science, 40(8), 999-1020.

Gerardi, K. S., and Shapiro, A. H. (2009). Does competition reduce price dispersion? New evidence from the airline industry. Journal of Political Economy, 117(1), $1-37$.

Goolsbee, A., and Syverson, C. (2008). How Do Incumbents Respond to the Threat of Entry? Evidence from the Major Airlines. Quarterly Journal of Economics, 123(4), 1611-1633.

Hotelling, H., 1929. Stability in competition. Economic Journal, 39, 41-57.

Lazarev, J. (2013). The welfare effects of intertemporal price discrimination: an empirical analysis of airline pricing in US monopoly markets. Working Paper, New York University.

Levin, Y., McGill, J., and Nediak, M. (2009). Dynamic pricing in the presence of strategic consumers and oligopolistic competition. Management Science, 55(1), $32-46$.

Martínez-de-Albéniz, V., and Talluri, K. (2011). Dynamic price competition with fixed capacities. Management Science, 57(6), 1078-1093.

Möller, M., and Watanabe, M. (2010). Advance purchase discounts versus clearance sales. Economic Journal, 120(547), 1125-1148.

Möller, M., and Watanabe, M. (2016). Competition in the presence of individual demand uncertainty. RAND Journal of Economics, 47(2), 273-292.

Nocke, V., Peitz, M., and Rosar, F. (2011). Advance-purchase discounts as a price discrimination device. Journal of Economic Theory, 146(1), 141-162.

Osborne, M. J., and Pitchik, C. (1985). The nature of equilibrium in a location model. International Economic Review, 27(1), 223-237.

Prescott, E. C. (1975). Efficiency of the natural rate. Journal of Political Economy, 83(6), 1229-1236.

Stavins, J. (2001). Price discrimination in the airline market: The effect of market concentration. Review of Economics and Statistics, 83(1), 200-202.

$\mathrm{Su}, \mathrm{X}$. (2007). Intertemporal pricing with strategic customer behavior. Management Science, 53(5), 726-741. 
Williams, K. (2018). Dynamic airline pricing and seat availability. Cowles Foundation Discussion Paper No. 2103.

Windle, R., and Dresner, M. (1995). The short and long run effects of entry on US domestic air routes. Transportation Journal, 14-25.

Windle, R., and Dresner, M. (1997). Competitive responses to low cost carrier entry. Transportation Research Part E: Logistics and Transportation Review, 35(1), 5975.

Zhao, W., and Zheng, Y. S. (2000). Optimal dynamic pricing for perishable assets with nonhomogeneous demand. Management Science, 46(3), 375-388. 